\title{
GSH-triggered Sequential Catalysis for Tumor Imaging and Eradication Based on Star-like Au/Pt Enzyme Carrier System
}

\author{
Amin Zhang ${ }^{1,2}$, Qian Zhang ${ }^{1,2}$, Gabriel Alfranca ${ }^{1,4}$, Shaojun Pan ${ }^{2,3}$, Zhicheng Huang ${ }^{1,2}$, Jin Cheng ${ }^{1,2}$, Qiang Ma ${ }^{5}$, Jie Song ${ }^{1,2}$ \\ Yunxiang Pan ${ }^{1,2}$, Jian $\mathrm{Ni}^{1}{ }^{1,2}$, Lijun Ma $(\square)$, Daxiang Cuii ${ }^{1,2,3}(\square)$ \\ ${ }^{1}$ Institute of Nano Biomedicine and Engineering, Shanghai Engineering Research Center for Intelligent Diagnosis and Treatment Instrument, \\ Department of Instrument Science and Engineering, School of Electronic Information and Electrical Engineering, Shanghai Jiao Tong University, \\ 800 Dongchuan RD, Shanghai 200240, P.R. China. \\ ${ }^{2}$ National Center for Translational Medicine, Collaborative Innovational Center for System Biology, Shanghai Jiao Tong University, 800 \\ Dongchuan Road, Shanghai 200240, P. R. China. \\ ${ }^{3}$ School of Biomedical Engineering, Shanghai Jiao Tong University, Shanghai 200240, P. R. China \\ ${ }_{4}^{4}$ Instituto de Ciencia de Materiales de Aragón (ICMA), CSIC/Universidad de Zaragoza, C/Pedro Cerbuna 12, 50009 Zaragoza, Spain \\ ${ }^{5}$ Department of Tumor of Xintai People's Hospital, Xintai 271200, Shangdong Province, P. R. China \\ ${ }^{6}$ Department of Tumor in Tongren Hospital, Shanghai Jiao Tong University School of Medicine, 1111 XianXia Road, Shanghai200336, China.
}

(C) Tsinghua University Press and Springer-Verlag GmbH Germany, part of Springer Nature 2019

Received: day month year / Revised: day month year / Accepted: day month year (automatically inserted by the publisher)

\begin{abstract}
Distinctively different metabolism between tumor cells and normal cells endows tumor tissues unique microenvironment. In this regard, we have successfully prepared a sequential catalytic platform based on Au/Pt star for tumor theragnostic. The multifunctional probes consisted in a gold/platinum star-shaped core (Au/Pt star) conjugated with a GSH-sensitive disulfide bond (S-S), a targeting ligand (rHSA-FA), a near-infrared fluorophore (IR780) and glucose oxidase (GOx). When systemically administered in a xenografted murine model, the probes specifically targeted the tumor sites. As the disulfide linker was cleaved by intracellular GSH, the IR780 molecules could be released for PTT\&PDT and imaging. Subsequently, the Pt nanolayer of the Au/Pt star core and the GOx formed a sequential catalytic system: GOx effectively catalyzed intracellular glucose by consuming oxygen to generate $\mathrm{H}_{2} \mathrm{O}_{2}$ and enhance the local acidity, and the Pt layer exhibited peroxidase-like property to catalyze $\mathrm{H}_{2} \mathrm{O}_{2}$ producing toxic $\cdot \mathrm{OH}$ for tumor oxidative damage. Here we demonstrated that our probes simultaneously possessed a GSH-sensitive release, real-time imaging ability, and synergetic cancer starving-like therapy/enzyme oxidative therapy/PTT/PDT features, which provides a potential strategy for effective tumor theragnostic.
\end{abstract}

\section{KEYWORDS}

Au/Pt star, GSH-responsive, GOx, peroxidase, sequential nanocatalyst, cancer starving-like therapy, enzyme oxidative therapy, PTT\&PDT

\section{Introduction}

Cancer, regarded as one of the deadliest diseases worldwide, has aroused numerous research attentions in developing effective therapy methods $[1,2]$. And, traditional cancer therapy modality is mostly limited to monotherapy such as clinical operation, chemotherapy and radiotherapy, which might also induce unfavorable tumor metastasis and cause some pain during the therapeutic process due to the complexity and diversity of tumor [3, 4]. Therefore, it is of crucial significance to develop multimodal therapeutic methods to reduce the death rate of cancer. Recently, emerging cancer therapy methods including photo-thermal therapy (PTT), photodynamic therapy (PDT) and chemotherapy possess imaging-guided and light-induced therapy efficacy, which flexibly integrate therapy with diagnosis $[5,6]$. PTT could transfer near-infrared light into heat to induce cancer cell apoptosis when using photothermic reagent [7], and PDT refers to reactive oxygen species (ROS) generation upon irradiation when employing photosensitizers $[8,9]$. The ideal photosensitizers should possess favorable pharmacokinetics and the perfect photothermic reagent could transfer absorbed near-infrared (NIR) light (700-900 nm) into heat with high safety. IR780 iodide, NIR dye, with good quantum yield, deep tissue penetration and excellent stability, would be eminent fluorescence molecules for tumor imaging and PTT/PDT therapy $[7,10]$.

Besides, designing cancer therapeutic modalities based on unique tumor microenvironment (TME) is an outstanding strategy, where the cellular metabolism, acidic environment and concentration of some biological substance ( $\mathrm{GSH}, \mathrm{H}_{2} \mathrm{O}_{2}$, etc.) are distinctly different from those in normal tissues. GSH, a significant nonprotein biothiol, plays a vital role in regulating cell growth and maintaining redox homeostasis with a 4-fold higher concentration in tumor than that in normal cells $[11,12]$, and the intracellular

Address correspondence to Lijun Ma, 1jma56@126.com (L.J. Ma); Daxiang Cui, dxcui@sjtu.edu.cn (D.X. Cui) 
concentration of GSH reaches to 100- to 1000- times higher than that outside of cell $[8,13]$. Therefore, numerous stimuli-responsive nanoplatforms towards GSH for controllable drug releasing or therapeutic reagent delivery have been designed, which could realize favorable cancer therapy efficacy with low adverse effects. Glucose oxidase (GOx), naturally endogenous oxidoreductase with high biocompatibility and low toxicity, could selectively catalyze glucose to generate gluconic acid and hydrogen peroxide $\left(\mathrm{H}_{2} \mathrm{O}_{2}\right)$ in the presence of oxygen, which could strategically provide cancer therapeutic methods including cancer starving-like therapy by consuming glucose, hypoxia-activated therapy due to the decrement of oxygen, $\mathrm{pH}$-responsive drug release due to the generated gluconic acid, and toxic hydroxyl radicals $(\cdot \mathrm{OH})$ induced cancer cell apoptosis which were produced under light irradiation or via the reaction between nanozyme and elevated $\mathrm{H}_{2} \mathrm{O}_{2}$ [14-17]. Integrating GOx with nanozymes, hypoxia-activated fluorescence molecules, pH-responsive drug delivery system, GSH-responsive system, photothermic reagent or photosensitizers into one multifunctional nanoplatform could realize multimodal synergistic therapy with superadditive treatment effect, offering alternative strategies for cancer diagnosis and therapy [18].

"Artificial enzymes" or "nanozymes" refer to the nanomaterials with intrinsic enzyme-mimic catalytic activity and possess low cytotoxicity, robust stability and devisable enzymatic catalysis, which could be acted as promising alternatives for nature enzymes $[3,19,20]$. Commonly used nanozymes contain metal nanoparticles [21-23], semiconducting polymer [24, 25] and carbon nanomaterials [26] and so on, and are widely applied in biomedical assay and cancer therapy, etc. Interestingly, some designed nanozymes show peroxidase-like ability in tumor, which could catalyze intratumor $\mathrm{H}_{2} \mathrm{O}_{2}$ to produce $\cdot \mathrm{OH}$, and following induce the cancer cells apoptosis or necrosis [27, 28]. In recent years, gold $(\mathrm{Au})$ - and platinum $(\mathrm{Pt})$-based nanomaterials have drawn widespread interest due to their good biocompatible, high chemical stability, potential nanozyme catalytic activity and tunable plasmon properties in the NIR regions [29-31]. Star-shaped gold nanoparticles (Austar) show distinctive plasmon band in NIR window and high absorption in the NIR region, and are widely employed in bioimaging, cancer therapy and clinical assay [32, 33]. Pt nanoparticles possess unique peroxidase-mimic catalytic activity, which could catalyze the $\mathrm{H}_{2} \mathrm{O}_{2}$ to produce toxic $\cdot \mathrm{OH}$ in an acid condition $[34,35]$. Inspired by the unique features of $\mathrm{Au}$ and $\mathrm{Pt}$, asteroidal $\mathrm{Au} / \mathrm{Pt}$ nanostructures $(\mathrm{Au} / \mathrm{Pt}$ star) has been fabricated and possesses outstanding photothermal and peroxidase-like properties, providing a potentially applicable and combinational strategy for cancer therapy.

Herein, we firstly fabricated core-shell Au/Pt star enzyme carrier system, which possessed photothermal property from Au star core and peroxidase-like property from Pt shell. Then, L-Cysteine was crosslinked onto $\mathrm{Au} / \mathrm{Pt}$ star to generate functional groups including $-\mathrm{COOH}$ and $-\mathrm{NH}_{2}$. After covalently conjugating cystamine dihydrochloride and targeted complex rHSA-FA onto surface of $\mathrm{Au} / \mathrm{Pt}$ star in successive via EDC/NHS chemistry, the obtained nanocomposites (Au/Pt star@S-S@rHSA-FA) physically encapsulated IR780 iodide. Ultimately, endogenous oxidoreductase GOx was assembled onto above-acquired nanocomposites via GA to successfully construct multifunctional probes (Scheme 1A). As the probes were targeted to the gastric cancer tumor, IR780 molecules encapsulated in rHSA could release when disulfide linker was cleaved by intracellular GSH. Then, the synergetic catalysis reaction would occur including glucose depletion by GOx and $\mathrm{H}_{2} \mathrm{O}_{2}$ oxidation by $\mathrm{Pt}$, which could realize cancer starvation and $\cdot \mathrm{OH}$ induced cancer cells damage. And, under $808 \mathrm{~nm}$ laser irradiating, PTT therapy and PDT therapy could be achieved. In this work, the successfully prepared multifunctional probes $(\mathrm{Au} / \mathrm{Pt}$ star@S-S@rHSA-FA@IR780@GOx) could multirole as diagnostic probe for real-time imaging, photothermal reagent for PTT therapy, photosensitizer for PDT therapy, glucose consuming enzyme for starvation therapy and peroxidase-mimic ability for oxidative therapy (details are demonstrated in Scheme 1B), providing a promising strategy for eff ective tumor eradication.

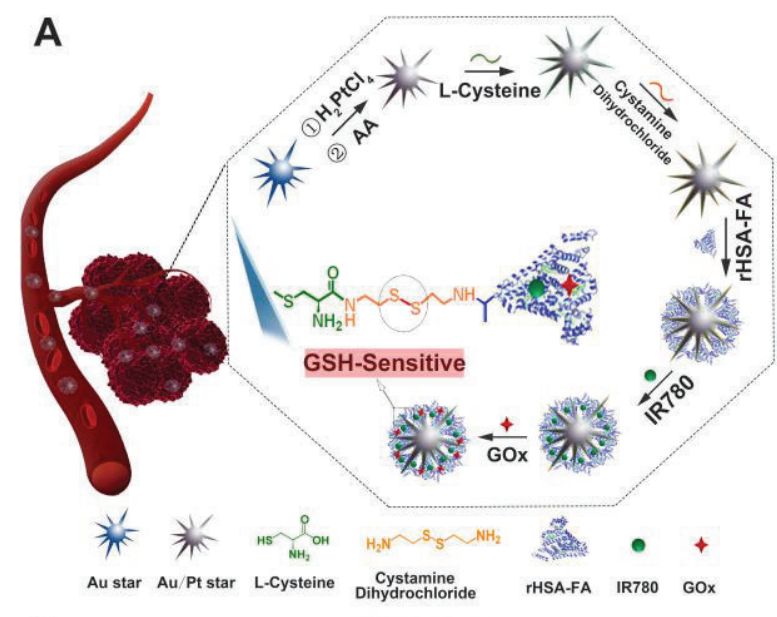

B

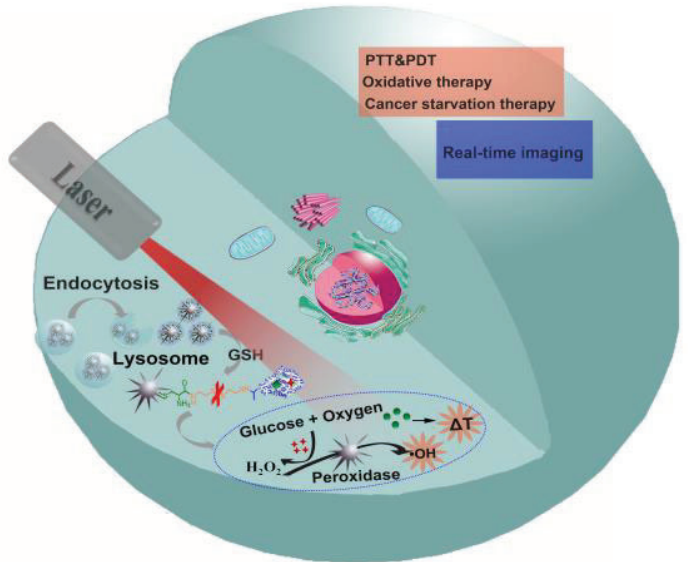

Scheme 1. (A) Schematic illustration for preparation procedure and (B) multifunctional application in vivo of probes.

\section{Experimental}

\subsection{Reagents and materials}

Gold chloride trihydrate $\left(\mathrm{HAuCl}_{4} \cdot 3 \mathrm{H}_{2} \mathrm{O}\right)$, silver nitrate $\left(\mathrm{AgNO}_{3}\right)$, L-ascorbic acid (AA), trisodium citrate, N-hydroxysuccinimide (NHS), N-(3-dimethylaminopropyl)-N'-ethylcarbodiimide hydrochloride (EDC), hexadecyltrimethylammonium bromide (CTAB), L-Cysteine, cystamine dihydrochloride and human serum albumin (HSA, $99.9 \%$ ) were all bought from Aladdin Reagent Co., Ltd. (Shanghai, China). Chloroplatinic acid hexahydrate $\left(\mathrm{H}_{2} \mathrm{PtCl}_{6} \cdot 6 \mathrm{H} 2 \mathrm{O}, 99.9 \%\right)$ was obtained from Adamas-beta. Folic acid (FA), sodium borohydride $\left(\mathrm{NaBH}_{4}\right)$, and anhydrous dimethyl sulfoxide (DMSO) were bought from Sinopharm Chemical Reagent Co. Ltd. (Shanghai, China). Chemical dye 
2-(4-Amidinophenyl)-6-indolecarbamidine

dihydrochloride

(DAPI), 2', 7'-dichlorofluorescein diacetate (DCFH-DA), Cell Counting Kit (CCK-8), Annexin V-FITC/PI Apoptosis Detection Kit and Calcein-AM/PI Double Stain Kit were provided by YEASEN Corporation (Shanghai, China). The cells were cultured by using Fetal bovine serum (FBS), Dulbecco's Modified Eagle's Medium (DMEM), Penicilline Streptomycin and Trypsine EDTA from Gibco Life Technologies. All chemical reagents employed in this work were of analytical grade. The pure water was applied in this study (18.2 M $\Omega$, Millipore Co., USA). Moreover, phosphate buffered solutions (PBS, $0.1 \mathrm{M}$ ) were obtained by using $0.1 \mathrm{M}$ $\mathrm{Na}_{2} \mathrm{HPO}_{4}$ and $0.1 \mathrm{M} \mathrm{KH}_{2} \mathrm{PO}_{4}$.

\subsection{Preparing asteroidal $\mathrm{Au} / \mathrm{Pt}$ bimetallic nanostructures (Au/Pt star).}

The asteroidal $\mathrm{Au} / \mathrm{Pt}$ bimetallic nanostructures $(\mathrm{Au} / \mathrm{Pt}$ star) used as carriers, photothermal regents and catalysis were prepared by two steps: (i) the synthesis of asteroidal Au nanoparticles (Au star) and (ii) growth of Pt nanolayer on the surface of Au star. The Au star nanoparticles were synthesized according to a previously reported method with slight modifications [32]. Firstly, little gold nanospheres acted as seeds were generated by the chemical reaction of $\mathrm{HAuCl}_{4}$ with trisodium citrate. Briefly, $15 \mathrm{~mL}$ trisodium citrate solution $(1 \%$ ) was quickly added into $100 \mathrm{~mL}$ boiling $1 \mathrm{mM} \mathrm{HAuCl}_{4}$ solution with stirring when the color was changed into wine red, indicating the successful generation of gold seeds. Subsequently, $400 \mathrm{~mL} \mathrm{HAuCl}_{4}(0.25 \mathrm{mM})$ was quickly mixed with $4 \mathrm{~mL}$ freshly prepared gold seeds, $4 \mathrm{~mL} \mathrm{HCl}(1 \mathrm{M})$ and $2 \mathrm{~mL}$ silver nitrate $(3 \mathrm{mM})$ in succession under stirring. After that, $2 \mathrm{~mL}$ ascorbic acid $(0.1 \mathrm{M})$ was added into above-obtained reaction precursor with stirring for $1 \mathrm{~min}$ to synthesize the $\mathrm{Au}$ star. To further prepare asteroidal $\mathrm{Au} / \mathrm{Pt}$ bimetallic nanostructures, $400 \mathrm{~mL}$ Au star solution were firstly mixed with $20 \mathrm{~mL}$ CTAB $(0.1 \mathrm{M})$ for $3 \mathrm{~h}$ reaction. Then, the $\mathrm{CTAB}$ attached $\mathrm{Au}$ star were centrifuged to remove impurities $(10000 \mathrm{rpm} / \mathrm{min}, 10 \mathrm{~min})$. Afterward, the centrifugation-acquired $\mathrm{Au}$ star was washed with deionized water for three times and redispersed into $100 \mathrm{~mL} \mathrm{CTAB}$ solution $(1 \mathrm{mM})$ with another $2 \mathrm{~h}$ stirring at $27^{\circ} \mathrm{C}$. Following that, $187.5 \mu \mathrm{L} \mathrm{HPtCl}_{4}$ $(2 \mathrm{mM})$ and $300 \mu \mathrm{L} \mathrm{AA}(0.1 \mathrm{M})$ were added into the above Au star solution, and the mixture was stirred vigorously at a $27{ }^{\circ} \mathrm{C}$ water bath. Within $12 \mathrm{~h}$ reaction, the final products named as $\mathrm{Au} / \mathrm{Pt}$ star were successively centrifuged, washed with water $\left(27^{\circ} \mathrm{C}\right)$, and dissolved into $100 \mathrm{~mL}$ PBS for further use.

\subsection{Fabricating Au/Pt star@S-S@rHSA-FA nanocomposites}

The Au/Pt star@S-S@rHSA-FA nanocomposites were fabricated by systematical functionalizations (showed in Scheme 1A): (i) crosslinking L-Cysteine; (ii) conjugating cystamine dihydrochloride; (iii) generation of rHSA-FA composites; (iv) functionalizing $\mathrm{Au} / \mathrm{Pt}$ star with rHSA-FA. Crosslinking L-Cysteine on the surface of Au/Pt star. At first, $500 \mathrm{mg}$ L-Cysteine was added into the above-acquired $\mathrm{Au} / \mathrm{Pt}$ star solution, followed by reacting for $2 \mathrm{~h}$. Conjugating cystamine dihydrochloride onto L-Cysteine modified Au/Pt star. After centrifuged by $10000 \mathrm{rpm} / \mathrm{min}$ for 3 mins, the L-Cysteine-conjugated $\mathrm{Au} / \mathrm{Pt}$ star was dissolved into 20 $\mathrm{mL}$ PBS (0.1 M, pH 7.4), and then mixed with EDC (86.3 mg), NHS $(200 \mathrm{mg})$ and cystamine dihydrochloride $(500 \mathrm{mg})$ to produce a GSH-sensitive disulfide linkage (Au/Pt star@S-S). The reaction system was stirred in dark at a $27{ }^{\circ} \mathrm{C}$ water bath for $6 \mathrm{~h}$. As the reaction finished, the centrifuged precipitate was washed by PBS three times and following resuspended in $20 \mathrm{~mL}$ PBS $(0.1 \mathrm{M}, \mathrm{pH}$ 7.4). Generation of rHSA-FA composites. Target molecule folic acid (FA) was firstly activated and purified via our previous works to synthesize FA-NHS [36]. Meanwhile, reduced human serum albumin (rHSA) was synthesized by mixing freshly prepared $\mathrm{NaBH}_{4}(1 \mathrm{M}, 250 \mu \mathrm{L})$ with HSA solution $(4 \mathrm{mg} / \mathrm{mL}, 10 \mathrm{~mL})$ for 2 $\mathrm{h}$ stirring reaction. Afterward, $50 \mathrm{mg}$ freeze-dried FA-NHS was added into above-generated rHSA solution with continuously stirring for $4 \mathrm{~h}$. The final-synthesized rHSA-FA composites were collected by centrifugal ultrafiltration (Millipore, $3 \mathrm{~K}$ MWCO) and then lyophilized for further use. Functionalizing rHSA-FA. To construct rHSA-FA functionalized nanocomposites, $20 \mathrm{~mL} \mathrm{Au} / \mathrm{Pt}$ star@S-S solution was mixed with EDC (86.3 mg), NHS (200 mg) and rHSA-FA $(100 \mathrm{mg})$ with stirring for $6 \mathrm{~h}$ reaction. Lastly, rHSA-FA crosslinked Au/Pt star@S-S (Au/Pt star@S-S@rHSA-FA) were centrifugated, washed by PBS and freeze-dried for further use.

2.4 Loading IR780 molecules into Au/Pt star@S-S@rHSA-FA IR780 molecules were also loaded into Au/Pt star@S-S@rHSA-FA by physically encapsulating IR780 iodide into the hydrophobic cavity of HSA. In detail, $12.5 \mathrm{mg}$ IR780 firstly was dispersed in DMSO, and then mixed with $10 \mathrm{~mL}$ above-prepared $\mathrm{Au} / \mathrm{Pt}$ star@S-S@rHSA-FA solution (5 mg/mL) for 6 h stirring at $37{ }^{\circ} \mathrm{C}$. Then, the final resultant was centrifuged, washed by PBS for three times and redispersed into $5 \mathrm{~mL}$ PBS ( $\mathrm{pH} 7.4,0.1 \mathrm{M})$. Besides, the supernatant solution was collected to monitor unloaded IR780 and further calculate IR780 entrapment efficiency (EE) and loading rate (LR).

\subsection{Immobilizing GOx onto Au/Pt star@S-S@rHSA-FA and Au/Pt star@S-S@rHSA-FA@IR780}

GOx acted as an endogenous oxidoreductase could effectively consume glucose in the inner of tumor to produce $\mathrm{H}_{2} \mathrm{O}_{2}$ and gluconic acid. In this study, we immobilize GOx onto $\mathrm{Au} / \mathrm{Pt}$ star@S-S@rHSA-FA and Au/Pt star@S-S@rHSA-FA@IR780 by using glutaraldehyde (GA). In brief, $1 \mathrm{~mL}$ GA (50\%) solution was respectively added into $10 \mathrm{~mL}$ Au/Pt star@S-S@rHSA-FA (5 mg/mL in PBS) and 10 mL Au/Pt star@S-S@rHSA-FA@IR780 $(6.1 \mathrm{mg} / \mathrm{mL}$ in PBS) solution. After $20 \mathrm{~min}$ stirring, $1 \mathrm{~mL}$ GOx solution $(6 \mathrm{mg} / \mathrm{mL}$ in PBS) was added into the mixture for $6 \mathrm{~h}$ reaction. Finally, the product was successively centrifuged, washed by PBS and redispersed into $10 \mathrm{~mL}$ PBS $(\mathrm{pH} 7.4,0.1 \mathrm{M})$ for further use.

The entrapment efficiency (EE) and loading rate (LR) of IR780 molecules in this study were calculated referring to following equations:

EE $(\%)=($ Weight of IR780 in Au/Pt star@S-S@rHSA-FA@IR780@GOx nanoprobes) / (Weight of IR780 added initially) $\times 100 \%$

LR $(\%)=$ (Weight of loaded IR780) $/$ (Weight of $\mathrm{Au} / \mathrm{Pt}$ star@S-S@rHSA-FA@IR780@GOx)×100\%

\subsection{Characterization of different nanomaterials}

The morphological and structural information of various materials was investigated by field emission transmission electron microscopy (FE-TEM, Talos F200X). The zeta potentials of various materials were carried out on a zeta potential/particle sizer (PSS Nicomp, Santa Barbara, CA, USA). The UV-vis 
spectrophotometer (Varian Inc., Palo Alto, CA, USA) and Fourier transform infrared spectrometer (FTIR, Nicolet 6700) was carried out to monitor the assembly process of probes. The fluorescence spectrum of different nanomaterials was measured on a spectrofluorometer (Hitachi FL-4600).

\subsection{Peroxidase-like enzymatic catalysis property of various materials}

The peroxidase-like enzymatic catalysis ability of various materials was investigated by recording the UV-Vis absorbance peaks of oxidized TMB. Briefly, the nanomaterials including $\mathrm{Au} / \mathrm{Pt}$ star and Au/Pt star@S-S@rHSA-FA were respectively dissolved into NaAc buffer (0.1 M, pH 6.0) in presence of TMB $(0.416 \mathrm{mM})$ and $\mathrm{H}_{2} \mathrm{O}_{2}(100 \mu \mathrm{M})$. After 10 min reaction, the reaction solution was performed on a UV-vis spectrophotometer to show the catalysis ability. To further study the effect of $\mathrm{pH}$ on the catalysis system, $1.0 \mathrm{~mL} \mathrm{NaAc}(0.1 \mathrm{M})$ buffer solution at various $\mathrm{pH}$ (4.5 to 6.0) was employed to dissolve $\mathrm{Au} / \mathrm{Pt}$ star in presence of $\mathrm{TMB}$ $(0.416 \mathrm{mM})$ and $\mathrm{H}_{2} \mathrm{O}_{2}(100 \mu \mathrm{M})$, and the UV-Vis absorbance spectra at various time were recorded.

\subsection{Hydroxyl radical $(\bullet \mathrm{OH})$ analysis}

Terephthalic acid (TA) could be used to capture $\cdot \mathrm{OH}$ and following produced 2-hydroxy terephthalic acid, which displayed an obvious emission fluorescence around $435 \mathrm{~nm}$ under $315 \mathrm{~nm}$ excitation while negligible fluorescence produced by TA. Briefly, $1.0 \mathrm{~mL} 0.1 \mathrm{M} \mathrm{NaAC}$ buffer in $\mathrm{pH} 6.0$ was applied to dissolve various materials. And then, $\mathrm{H}_{2} \mathrm{O}_{2}$ (final concentration: $100 \mu \mathrm{M}$ ) or glucose (final concentration: $5 \mathrm{mM}$ ) was added into the reacted system for $30 \mathrm{~min}$ or $3 \mathrm{~h}$ incubation in respective. After interaction, $1 \mathrm{~mL}$ TA solution ( $4 \mathrm{mM}$ dissolved into $10 \mathrm{mM} \mathrm{NaOH}$ ) was mixed with above-acquired solution for another $30 \mathrm{~min}$ reaction under shaking. Ultimately, the obtained solution was testified on a fluorescent spectrophotometer.

\subsection{Singlet oxygen investigation}

The singlet oxygen sensor green (SOSG) regent is a useful tool for ${ }^{1} \mathrm{O}_{2}$ detection. In this work, $2.5 \mu \mathrm{M}$ SOSG was applied to detect the generated ${ }^{1} \mathrm{O}_{2}$ in different systems including free IR780 (acted as control) and probes (equivalent $50 \mu \mathrm{g} / \mathrm{mL}$ IR780) with or without $5 \mathrm{~min} 808 \mathrm{~nm}$ irradiation. Besides, the systems were performed on a fluorescent spectrophotometer $(\lambda e x: 494 \mathrm{~nm})$ to collect SOSG fluorescence.

\subsection{The laser-induced temperature change of probes in vitro}

The $808 \mathrm{~nm}$ laser-induced temperature change prolonging with the time in PBS (used as control), probes (equivalent IR780 dosage: $20 \mu \mathrm{g} / \mathrm{mL}$ and $60 \mu \mathrm{g} / \mathrm{mL}$ ) groups was monitored by using an infrared imaging camera.

\subsection{In Vitro GSH-Responsive Behavior of $\mathrm{Au} / \mathrm{Pt}$ star@S-S@rHSA-FA@IR780}

The responsive behavior of $\mathrm{Au} / \mathrm{Pt}$ star@S-S@rHSA-FA@IR780@GOx toward GSH was investigated by measuring fluorescence intensity after IR780 releasing from the probes in vitro. In brief, $10 \mathrm{~mL} \mathrm{Au} / \mathrm{Pt}$ star@S-S@rHSA-FA@IR780@GOx solution ([IR780]: $50 \mu \mathrm{g} / \mathrm{mL}$ ) were respectively treated by $0 \mathrm{mM}$ GSH, $10 \mathrm{mM} \mathrm{GSH}$ and $50 \mathrm{mM}$
$\mathrm{GSH}$, and then the mixture was shaking with $200 \mathrm{rpm} / \mathrm{min}$. At various time points, the solution was centrifuged by centrifugal ultrfiltration (Amicin Ultr-15, Millipore, $100 \mathrm{~K}$ MWCO) and following diluted into 10 times. Finally, the solution was quantitatively calculated by a fluorescent spectrophotometer.

The release percentages ( $\mathrm{RP}, \mathrm{w} / \mathrm{w} \%)$ were calculated as the following equation:

RP_IR780(\%) $=($ Release weight of IR780) / (Initial weight of IR780 in Au/Pt star@S-S@rHSA-FA@IR780@GOx) ×100\%

\subsection{Cell culture}

The cell line used here was gastric cancer cells (MGC-803) and cultured in DMEM containing fetal bovine serum $(\mathrm{v} / \mathrm{v}=10 \%)$, penicillin $(100 \mathrm{U} / \mathrm{mL})$ and streptomycin $(0.1 \mathrm{mg} / \mathrm{mL})$ at $37{ }^{\circ} \mathrm{C}$ with $5 \% \mathrm{CO}_{2}$ (defined as complete medium). And the MGC- 803 cells were subcultured by using Trypsin/EDTA. When the cells were in the logarithmic growth phase, they were used in this experiment.

\subsection{Cellular Uptake Assay}

For cellular uptake study, microscopy and FC were synergistically employed in this study. For qualitatively observe the cellular uptake, the cells were firstly cultured in glass coverslips $(14 \mathrm{~mm})$ for $24 \mathrm{~h}$. Following, free IR780 $(3 \mu \mathrm{g} / \mathrm{mL})$ and probes $(18 \mu \mathrm{g} / \mathrm{mL})$ were respectively added and interacted with cells. At various periods (1, 4 and $12 \mathrm{~h}$ ), the cells were washed by PBS, fixed by $4 \%$ paraformaldehyde for $30 \mathrm{~min}$ and stained with DAPI for $5 \mathrm{~min}$ in dark. After washed by PBS gently, the cells were observed by a confocal laser scanning microscopy (CLSM) (DAPI, excitation: $405 \mathrm{~nm}$ and emission: 440 to $470 \mathrm{~nm}$; IR780 in probes, excitation: $633 \mathrm{~nm}$ and emission: 700 to $800 \mathrm{~nm}$ ).

To quantitatively show the endocytosis towards probes, the cells $\left(1 \times 10^{5} /\right.$ well $)$ were cultured in a 6 -well plate for $24 \mathrm{~h}$, and then the cells were interacted with free IR780 $(3 \mu \mathrm{g} / \mathrm{mL})$ and probes $(18$ $\mu \mathrm{g} / \mathrm{mL}$ ) for 1,4 and $12 \mathrm{~h}$. Then, the cells were collected by using trypsin. After washed by PBS, the cells were resuspended into 1.5 $\mathrm{mL}$ PBS for FC assay. The signal in FL3-H channel was monitored to study endocytosis of probes.

\subsection{Cytotoxicity study of various materials}

Cytotoxicity investigation was of crucial importance in evaluating the biocompatibility, safety and therapeutic efficacy of final-obtained probes. In this work, CCK-8 Assays, Apoptosis Assay and Calcein-AM/PI Staining Assay were synchronously utilized to assess the dark toxicity and phototoxicity of probes to cells.

CCK-8 experiment. In detail, MGC- 803 cells $\left(5 \times 10^{3}\right.$ per well) were firstly cultured in 96-cell plates for $24 \mathrm{~h}$. Then, the culture medium of cells was replaced by $100 \mu \mathrm{L}$ complete medium in low glucose containing PBS, IR780,Au/Pt star@S-S@rHSA-FA@GOx or Au/Pt star@S-S@rHSA-FA@IR780@GOx at various concentrations range: $0.25-3 \mu \mathrm{g} / \mathrm{mL}$ of IR780 and $1.25-15$ $\mu \mathrm{g} / \mathrm{mL}$ of Au/Pt star@S-S@rHSA-FA@GOx. After 8 h endocytosis, the cells were washed by fresh complete medium and then were irradiated with or without $808 \mathrm{~nm}$ laser $\left(1.0 \mathrm{~W} / \mathrm{cm}^{2}, 5 \mathrm{~min}\right)$. After that, the cells were cultivated for another $8 \mathrm{~h}$. Finally, the cells' viabilities were analyzed by standard CCK- 8 assay and further 
investigated on a Microplate Reader by using a $450 \mathrm{~nm}$ absorbance. The cell viability was studied via formula:

$$
\text { Cell viability }=\left(\mathrm{OD}_{\text {Experimental group }}-\mathrm{OD}_{\mathrm{Blank}}\right) /\left(\mathrm{OD}_{\text {Control }}-\mathrm{OD}_{\mathrm{Blank}}\right) \times 100 \%
$$

Apoptosis Assay. The apoptosis situation of cells in various experimental groups was performed on a BD FACSCalibur, where the Annexin V-FITC/PI Apoptosis Detection Kit (Yeasen, Shanghai) was carried out to stain cells. Briefly, MGC-803 cells were firstly seeded into a 6-cell plate with a density of $1 \times 10^{5}$ cells per well for $24 \mathrm{~h}$ and then replaced by complete medium in low glucose contained PBS, IR780, Au/Pt star@S-S@rHSA-FA@GOx and probes (IR780: $3 \mu \mathrm{g} / \mathrm{mL}$, Au/Pt star@S-S@rHSA-FA@GOx: 15 $\mu \mathrm{g} / \mathrm{mL}$ ) for $8 \mathrm{~h}$ incubation. After washed with fresh complete medium and irradiated with or without $808 \mathrm{~nm}$ laser $\left(1.0 \mathrm{~W} / \mathrm{cm}^{2}, 5\right.$ $\mathrm{min})$, the cells were incubated in dark for another $8 \mathrm{~h}$. Following that, the cells were collected and dyed by Annexin V $(5 \mu \mathrm{L})$ and PI $(10 \mu \mathrm{L})$ in dark for $20 \mathrm{~min}$. Finally, the dyed cells were analyzed on flow cytometry (FC) and the recorded data were investigated by FlowJo 10.0 software.

Calcein-AM and PI Staining Assay. To observe the live/dead situation of MGC-803 cells after interacted with probes by naked eye, the probes treated cells were stained by calcein-AM and PI and subsequently observed on a fluorescence microscope. In brief, the cells $\left(1.0 \times 10^{4}\right.$ cells/well $)$ were incubated in 6 -cell plates for $24 \mathrm{~h}$. Then, the cells were treated with probes $(18 \mu \mathrm{g} / \mathrm{mL})$ and sustained $8 \mathrm{~h}$ incubation. Following washed and replaced by fresh medium, the cells were treated with or without irradiation. After 12 $\mathrm{h}$ incubation in dark, the cells were stained by calcein-AM $(2.0 \mu \mathrm{M})$ and PI $(1.5 \mu \mathrm{M})$ for $15 \mathrm{~min}$ at $37^{\circ} \mathrm{C}$. Ultimately, after washed by PBS, the cells were imaged at a fluorescence microscope.

\subsection{Animals and tumor model}

The female nude mice (5 weeks' old, 15 18 g) were all provided by Shanghai Jiesijie Laboratory Animal Co. Ltd. (China). And all mice were raised referring to the guidelines of Approval of institutional Animal Care and Use Committee of Shanghai Jiao Tong University. To establish tumor model, MGC-803 cells $(4 \times$ $10^{6}$ cells in $100 \mu \mathrm{L}$ complete medium) were injected into right leg of mice. As the tumor size was near to $100 \mathrm{~mm}^{3}$, the mice were used for experiment.

\subsection{In vivo and ex vivo fluorescence imaging}

To real-time investigate the targeted efficacy of prepared probes (Au/Pt star@S-S@rHSA-FA@GOx@IR780), NIR fluorescence imaging of mice at various time points was observed and imaged by a imaging system (Bruker In-Vivo F PRO, Billerica, MA, USA), where the parameters were set up as followed: excitation at 720/20 $\mathrm{nm}$, emission at 790/30 nm, exposure time in $60 \mathrm{~s}$. Briefly, $100 \mu \mathrm{L}$ of free IR780 and probes (equivalent IR780 concentration: $5 \mathrm{mg} / \mathrm{kg}$ ) were intravenously injected into the tumor-bearing mice. Then, the time-course fluorescence images of tumor were recorded from 2 to $60 \mathrm{~h}$.

Additionally, the mice treated by IR780 and probes were sacrificed at $48 \mathrm{~h}$ and the tissues (heart, liver, spleen, lung, kidney and tumor) were imaged with the same parameters as mentioned above. Moreover, the fluorescence intensity of various tissues was recorded by a Bruker Molecular Imaging Software.

\subsection{In vivo synergistic therapy}

To evaluate the therapy efficacy of probes, the tumor-bearing mice were intravenously treated with $100 \mu \mathrm{L}$ of PBS (control group), free IR780, Au/Pt star@S-S@rHSA-FA@GOx and Probes(equivalent IR780 concentration: $5 \mathrm{mg} / \mathrm{kg}$ and equivalent Au/Pt star@S-S@rHSA-FA@GOx concentration: 25 mg/kg) respectively. After $36 \mathrm{~h}$ post-injection, the tumor in various groups was irradiated by $808 \mathrm{~nm}$ laser $\left(1.0 \mathrm{~W} / \mathrm{cm}^{2}, 5 \mathrm{~min}\right)$. Meanwhile, infrared camera was employed to record the temperature fluctuation in tumor sites and infrared pictures of mice. Besides, the relative tumor size and body weight were monitored every three days within 15 days. Moreover, the information of tumors in different experimental groups was also monitored every three days within 15 days by a camera. After 15 days' experiment, the main organs in PBS and probes treated mice were excised, dyed with hematoxylin and eosin (H\&E), and further studied morphological features of each group.

\subsection{Statistical Analysis}

All results described in this work were showed as means $\pm \mathrm{SD}$.

\section{Results and discussion}

\subsection{Characterization of various materials}

The synthesis process of probes was presented in Scheme 1A. To testify the successful preparation of enzyme carrier system $\mathrm{Au} / \mathrm{Pt}$ star, the morphologies and structural information of $\mathrm{Au}$ star and $\mathrm{Au} / \mathrm{Pt}$ star were investigated by a high-resolution transmission electron microscopy (HR-TEM). As illustrated in Fig. 1A, the asteroidal structure of $\mathrm{Au}$ star could be observed, endowing excellent growth platform for Pt nanoparticles. As observed in Fig. 1B, the morphological structure and size of the $\mathrm{Au} / \mathrm{Pt}$ star were similar to that of $\mathrm{Au}$ star, showing star-like shape with a uniformly average size of ca. $75 \mathrm{~nm}$ according to the size distribution in Fig. S1 Moreover, as shown in the enlarged TEM picture of $\mathrm{Au} / \mathrm{Pt}$ star (Fig. 1C), a rough structure could be observed on the surface of $\mathrm{Au}$ star, suggesting the successful formation of Pt nanoparticles based on Au star.

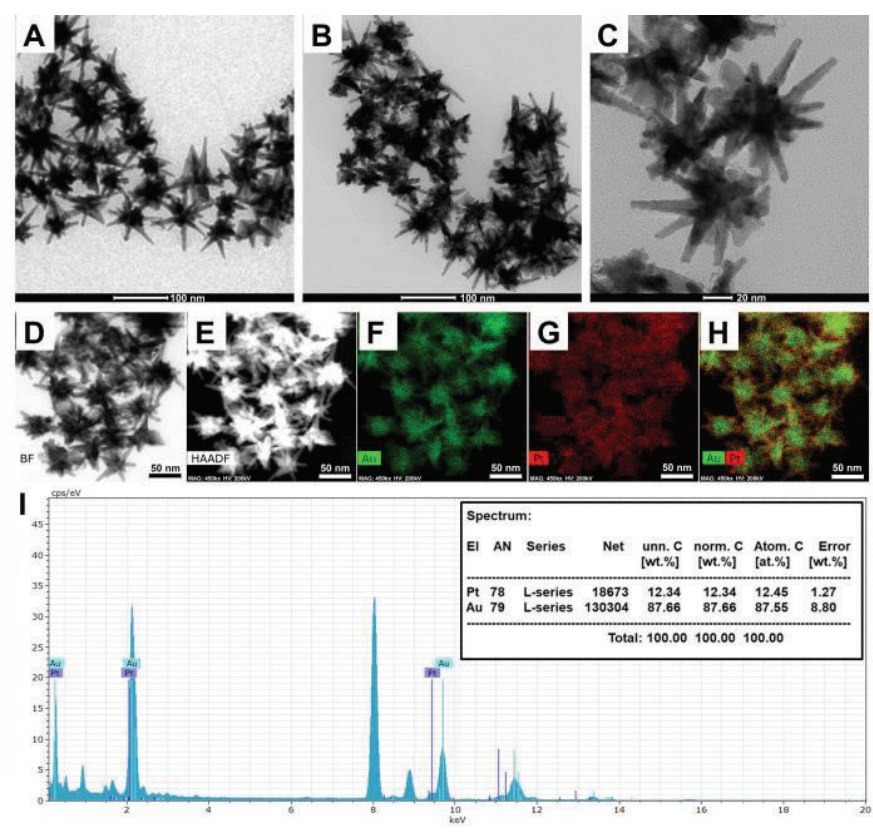


Fig. 1. HR-TEM images of (A) Au star and (B) Au/Pt star. (C) enlarged TEM picture of $\mathrm{Au} / \mathrm{Pt}$ star. (D) BF-STEM and (E) HAADF-STEM pictures of $\mathrm{Au} / \mathrm{Pt}$ star. (F-H) The EDX elemental mapping images of $\mathrm{Au} / \mathrm{Pt}$ star. (I) energy-dispersive X-ray spectroscopy of Au/Pt star.

And the BF-STEM (Fig. 1D) and HAADF-STEM (Fig. 1E) pictures of $\mathrm{Au} / \mathrm{Pt}$ star further validated the star-like structure of $\mathrm{Au} / \mathrm{Pt}$ bimetallic carrier. Additionally, the energy-dispersive X-ray spectroscopy (EDX) elemental mapping clearly presented the distribution of $\mathrm{Au}$ and $\mathrm{Pt}$ atoms in $\mathrm{Au} / \mathrm{Pt}$ bimetallic nanostructures (Fig. 1F- H), showing an asteroidal Au core and star-like Pt shell in the $\mathrm{Au} / \mathrm{Pt}$ star. From energy-dispersive X-ray spectroscopy (Fig. 1I), the mass ratio of $\mathrm{Pt} / \mathrm{Au}$ in $\mathrm{Au} / \mathrm{Pt}$ star carrier could be approximately calculated as $1 / 7$.

To monitor the successful modification of the probes, the systematic change of the nanomaterials was monitored by UV-vis spectroscopy, Fourier Transform infrared spectrum (FTIR) and zeta potential measurement. As showed in the UV-vis measurement (Fig. 2A), the obtained gold nanoparticles displayed a specific peak at $520 \mathrm{~nm}$ (curve a). When the Au star was produced by using $\mathrm{Au}$ NPs, there was a specific LSPR peak around $800 \mathrm{~nm}$ (curve b), indicating the successful generation of $\mathrm{Au}$ star core. Followingly generating a layer of Pt shell, there was still an obvious LSPR peak around $800 \mathrm{~nm}$, indicating the reservation of star-like structure in the nanoparticles (curve c). After functionalizing a targeted complex rHSA-FA on the surface of $\mathrm{Au} / \mathrm{Pt}$ star, there were typical absorption peak at $800 \mathrm{~nm}$ due to the existence of $\mathrm{Au} / \mathrm{Pt}$ star and additional absorption peaks at $280 \mathrm{~nm}$ and $346 \mathrm{~nm}$ which were corresponded to the absorption of rHSA and FA respectively, revealing the successful crosslinking of rHSA-FA (curve d). When GOx was covalently crosslinked with rHSA-FA (curve e), there was more obvious $280 \mathrm{~nm}$ peak due to GOx and rHSA, $346 \mathrm{~nm}$ corresponding to FA and $800 \mathrm{~nm}$ owing to $\mathrm{Au} / \mathrm{Pt}$ star. From the curve $\mathrm{f}$ in Fig. 2A, we could conclude that the fluorescence molecules IR780 showed a typical UV-vis absorption peak at 775 $\mathrm{nm}$. As the IR780 molecules have been loaded into the probes, there was a specific peak around 600 to $900 \mathrm{~nm}$ (curve g) with a red-shifted from 775 to $823 \mathrm{~nm}$ due to the accumulation of IR780, proving the successful encapsulation of IR780 into probes finally.

FTIR could provide accurate surficial information of nanomaterials. As shown in Fig. 2B, CTAB modified Au/Pt star (curve a) exhibited the same specific peaks at $2918 \mathrm{~cm}^{-1}$ and 1467 $\mathrm{cm}^{-1}$ as pure CTAB from the reported reference [37], which was attributed to the asymmetric stretching vibrations of $\mathrm{C}-\mathrm{CH}_{2}$ and the deformation of $-\mathrm{CH}_{2}$ - and $-\mathrm{CH}_{3}$. When the L-cysteine was attached to $\mathrm{Au} / \mathrm{Pt}$ star (curve b), there were specific peaks at $3449 \mathrm{~cm}^{-1}$ and $1630 \mathrm{~cm}^{-1}$ due to the formation of $-\mathrm{NH}_{2}$ and -COOH. Compared with the IR peaks in free cystamine in Fig. S2, new specific peak showed in $1638 \mathrm{~cm}^{-1}$ as the cystamine was crosslinked onto Au/Pt star@L-cys via EDC/NHS (curve c), indicating the successful generation of amido linkage between L-cysteine and Cystamine. In addition, a specific peak at $1638 \mathrm{~cm}^{-1}$ in curve $\mathrm{d}$ respectively relying on the generation of ester bond between rHSA-FA and Cystamine, and the peak at $1400 \mathrm{~cm}^{-1}$ was owing to the vibration of benzene ring in FA. Additionally, there was an obvious ester bond peak at $1638 \mathrm{~cm}^{-1}$ (curve e). Compared with curve e, as the IR780 molecules were loaded into $\mathrm{Au} / \mathrm{Pt}$ star@S-S@rHSA-FA@IR780@GOx, there were additional 1555, 1400,1371 , and $1252 \mathrm{~cm}^{-1}$ due to the stretching vibration of $\mathrm{C}=\mathrm{C}$ in IR780 (Fig. S2), indicating the successfully loading of IR780 into Au/Pt star@S-S@rHSA-FA@IR780@GOx. Moreover, the corresponding FTIR information of IR780 was displayed in curve d of Fig. S2.

In zeta potential measurement, we could clearly find the surface change during the fabrication process. As demonstrated in Fig 2C, the CTAB attached $\mathrm{Au} / \mathrm{Pt}$ star exhibited a positive potential at $29.38 \mathrm{mV}$, which was due to electropositivity of CTAB molecules. As the L-cysteine was crosslinked onto the $\mathrm{Au} / \mathrm{Pt}$ star, the potential of Au/Pt star@L-cys changed into a negative potential at -5.47, indicating the successfully assembling of L-cysteine. When the Cystamine molecules were crosslinked with Au/Pt star@L-cys by EDC/NHS chemistry (abbreviated as $\mathrm{Au} / \mathrm{Pt}$ star@L-cys@Cystamine), there was an obvious positive potential appeared at $15.73 \mathrm{mV}$ owing to the existence of terminal $-\mathrm{NH}_{2}$ groups in cystamine. After the rHSA-FA was attached onto the Au/Pt star@L-cys@Cystamine, the electronegative rHSA changed the potential into $-15.28 \mathrm{mV}$. As the IR780 molecules were loaded into Au/Pt star@L-cys@Cystamine@rHSA-FA, the potential has shifted to $-6.17 \mathrm{mV}$, suggesting the successful assemble of IR780. Finally, when the GOx was crosslinked to the $\mathrm{Au} / \mathrm{Pt}$ star@L-cys@Cystamine@rHSA-FA@IR780, the potential decreased to $-12.03 \mathrm{mV}$ due to the electronegative protein property of $\mathrm{GOx}$ (abbreviated as $\mathrm{Au} / \mathrm{Pt}$ star@S-S@rHSA-FA@IR780@GOx)._All above-mentioned potential results proved the systemically successful preparation of probes Au/Pt star@S-S@rHSA-FA@IR780@GOx. In addition, according to calibration curve between UV-vis absorbance intensity and IR780 concentrations (Fig. S3), the EE and LR of IR780 could be calculated into $88 \%$ and $16.67 \%$ in respective.
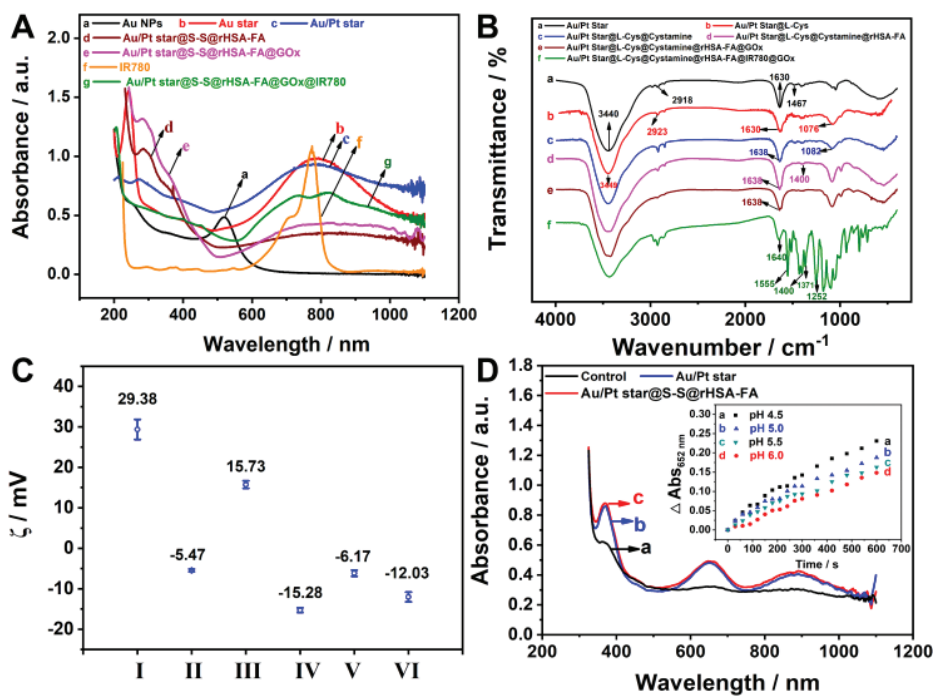

Fig. 2. Characterization of various materials: (A) UV-vis absorption spectra of Au NPs (a), Au star (b), Au/Pt star (c), Au/Pt star@S-S@rHSA-FA (d), Au/Pt star@S-S@rHSA-FA@GOx (e), IR780 (f), Au/Pt star@S-S@rHSA-FA@IR780@GOx (g). (B) FTIR spectra of various materials from a to $\mathrm{f}: \mathrm{Au} / \mathrm{Pt}$ star, $\mathrm{Au} / \mathrm{Pt}$ star@L-cys, $\mathrm{Au} / \mathrm{Pt}$ star@L-cys@Cystamine, Au/Pt star@L-cys@Cystamine@rHSA-FA, Au/Pt star@L-cys@Cystamine@rHSA-FA@GOx and Au/Pt star@S-S@rHSA-FA@IR780@GOx. (C) Zeta potentials of Au/Pt star (I), Au/Pt star@L-cys (II), Au/Pt star@L-cys@Cystamine (III), Au/Pt star@L-cys@Cystamine@rHSA-FA $\quad$ (IV), _ Au/Pt star@L-cys@Cystamine@rHSA-FA@IR780_ (V)_ and Au/Pt star@S-S@rHSA-FA@IR780@GOx (VI). (D) UV-vis absorption spectra of various systems after 10 min reaction: (a) TMB in presence of $\mathrm{H}_{2} \mathrm{O}_{2}$ (control), 
(b) TMB in presence of $\mathrm{H}_{2} \mathrm{O}_{2}$ and $\mathrm{Au} / \mathrm{Pt}$ star, (c) TMB in presence of $\mathrm{H}_{2} \mathrm{O}_{2}$ and $\mathrm{Au} / \mathrm{Pt}$ star@S-S@rHSA-FA in NaAc buffer (pH 6.0). Inset: UV-vis absorbance fluctuation of Au/Pt star@S-S@rHSA-FA at 652 nm in various pH value (4.5-6.0). Parameters: [TMB]: $0.416 \mathrm{mM},\left[\mathrm{H}_{2} \mathrm{O}_{2}\right]: 100 \mu \mathrm{M}$, [equivalent $\mathrm{Au} / \mathrm{Pt} \mathrm{star}]: 50 \mu \mathrm{g} / \mathrm{mL}$.

\subsection{Mimicking Enzymatic Activities}

The peroxidase-like property of $\mathrm{Au} / \mathrm{Pt}$ star and $\mathrm{Au} / \mathrm{Pt}$ star@S-S@rHSA-FA have been studied by oxidizing the tetramethylbenzidine (TMB) in the presence of $\mathrm{H}_{2} \mathrm{O}_{2}$, which would show a maximum absorbance at $652 \mathrm{~nm}$. As showed in Fig. 2D, no obvious $652 \mathrm{~nm}$ absorption peak showed in curve a (control group), while the Au/Pt star and Au/Pt star@S-S@rHSA-FA groups displayed specific absorption peak at $652 \mathrm{~nm}$ and the intensities were almost the same (curve $b$ and $c$ ), indicating favorable catalytic capacity of $\mathrm{Au} / \mathrm{Pt}$ star even though modifying a biolayer on its surface. Moreover, the absorbance fluctuation of $\mathrm{Au} / \mathrm{Pt}$ star@S-S@rHSA-FA at 652 nm in various pH value (4.5-6.0) prolonging with time were exhibited in the inset of Fig. 2D, and it could conclude that the acidic environment improved the peroxidase-like catalysis ability of $\mathrm{Au} / \mathrm{Pt}$ star.

Besides, the fluorescence of 2-hydroxy terephthalic acid collected from $\quad \mathrm{Au} / \mathrm{Pt} \quad \mathrm{star} @ S-\mathrm{S} @ \mathrm{rHSA}-\mathrm{FA}, \quad \mathrm{Au} / \mathrm{Pt}$ star@S-S@rHSA-FA@GOx and probes were almost same and much stronger than control group, which was attributed to that peroxidase-like $\mathrm{Au} / \mathrm{Pt}$ star could catalyze $\mathrm{H}_{2} \mathrm{O}_{2}$ to generate $\cdot \mathrm{OH}$ and the obtained $\cdot \mathrm{OH}$ could followingly react with HA to produce 2-hydroxy terephthalic acid (Fig. 3A). To further show the catalysis ability of GOx in probes toward glucose, various materials including Au/Pt star@S-S@rHSA-FA, Au/Pt star@S-S@rHSA-FA@GOx and probes were carried out to reacted with $5 \mathrm{mM}$ glucose and HA. As displayed in Fig. 3B, the fluorescence signals of 2-hydroxy terephthalic acid in $\mathrm{Au} / \mathrm{Pt}$ star@S-S@rHSA-FA@GOx and probes groups were much stronger than that in Au/Pt star@S-S@rHSA-FA, which was due to that GOx could firstly catalyze glucose to generate hydrogen peroxide $\left(\mathrm{H}_{2} \mathrm{O}_{2}\right)$ and the obtained $\mathrm{H}_{2} \mathrm{O}_{2}$ could be further reacted with $\mathrm{Au} / \mathrm{Pt}$ star to produce $\mathrm{OH}$ for 2-hydroxy terephthalic acid generation. However, a relatively moderate fluorescence signal of 2-hydroxy terephthalic acid could be observed in $\mathrm{Au} / \mathrm{Pt}$ star@S-S@rHSA-FA group, which might be attributed to potential enzymatic ability of Pt nanomaterials toward glucose as reported references [38, 39]. In addition, the control group showed no fluorescence intensity, proving that glucose could not produce $\cdot \mathrm{OH}$. All results indicated that surficial GOx in probes could effectively increase $\mathrm{H}_{2} \mathrm{O}_{2}$ concentration by catalyzing glucose and the inner $\mathrm{Au} / \mathrm{Pt}$ star possessed excellent peroxidase-like ability to generate $\cdot \mathrm{OH}$ in presence of $\mathrm{H}_{2} \mathrm{O}_{2}$, which could perform glucose-consuming induced starvation therapy and $\cdot \mathrm{OH}$ caused oxidative therapy for cancer.

\subsection{PDT and PTT study of probes in vitro}

IR780, NIR-absorbing fluorescent reagent, could be utilized for photodynamic reagent and photothermic reagent for tumor therapy under $808 \mathrm{~nm}$ laser irradiation. To study the PDT effect of probes (the generation of singlet oxygen), the SOSG reagent in $2.5 \times 10^{-6}$ $\mathrm{M}$ was carried out to monitor the production of singlet oxygen. As showed in Fig. 3C, there was negligible SOSG fluorescence observed in free IR780 and probes $(\mathrm{Au} / \mathrm{Pt}$ star@S-S@rHSA-FA@IR780@GOx) without808 nm irradiation. However, when the systems were irradiated under $808 \mathrm{~nm}$ laser $\left(1.0 \mathrm{~W} / \mathrm{cm}^{2}, 5 \mathrm{~min}\right)$, distinct fluorescence signals could be captured in both free IR780 and probes groups, indicating outstanding singlet oxygen generation of IR780 in probes when given $808 \mathrm{~nm}$ laser irradiation.

To testify the photothermal efficiency of final-acquired probes (Au/Pt star@S-S@rHSA-FA@IR780@GOx), the temperature fluctuations prolonging with time at different concentrations have been investigated under $808 \mathrm{~nm}$ laser $\left(1.0 \mathrm{~W} / \mathrm{cm}^{2}\right)$ irradiation. As showed in Fig. 3D, the control group (PBS) exhibited a mild temperature increment, while the probes $(20$ and $60 \mu \mathrm{g} / \mathrm{mL}$ of IR780) showed high temperature increasing from 22 to 41 and 22 to $54{ }^{\circ} \mathrm{C}$ respectively. The obvious temperature change in probes might be caused by the synergistically photothermal conversion ability from $\mathrm{Au} / \mathrm{Pt}$ star and IR780, suggesting eminent heat generation and the irreversible PTT therapeutic ability of probes.
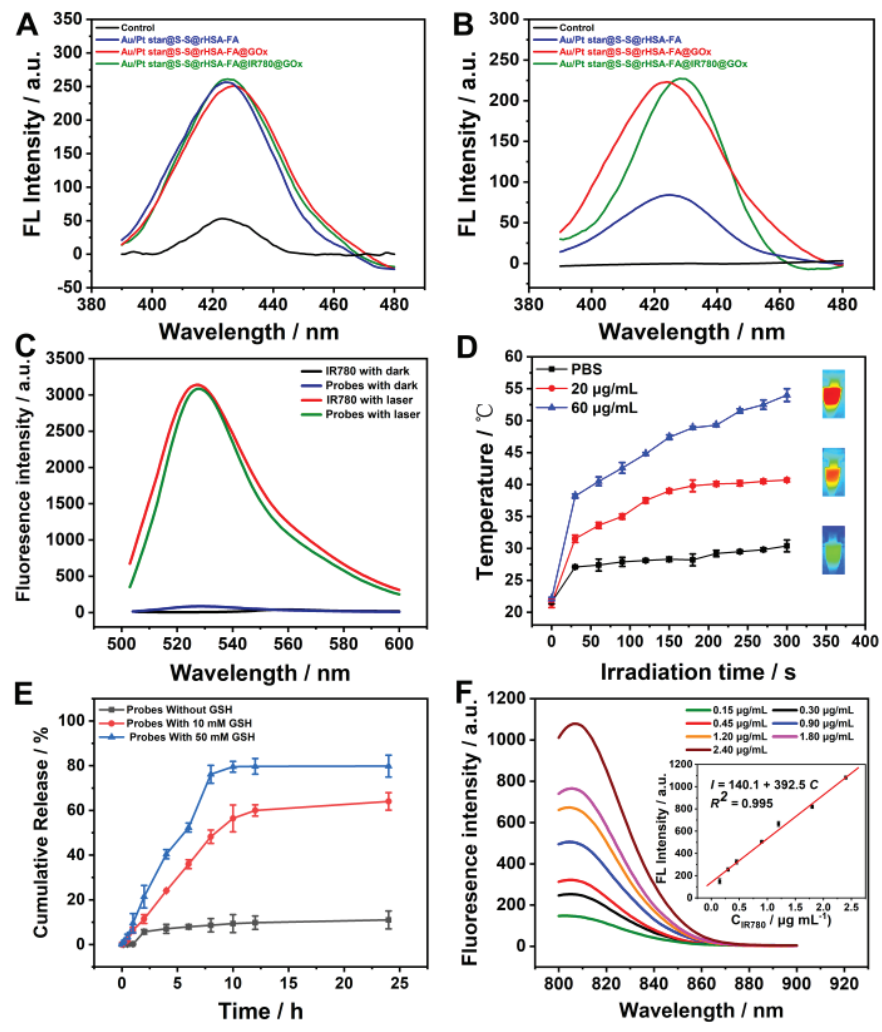

Fig. 3. $\mathrm{OH}$ detection in various systems: (A) fluorescence spectra of $\mathrm{H}_{2} \mathrm{O}_{2}+$ TA (control), $\mathrm{H}_{2} \mathrm{O}_{2}+\mathrm{Au} / \mathrm{Pt}$ star@S-S@rHSA-FA + TA, $\mathrm{H}_{2} \mathrm{O}_{2}+\mathrm{Au} / \mathrm{Pt}$ star@S-S@rHSA-FA@GOx + TA and $\mathrm{H}_{2} \mathrm{O}_{2}+\mathrm{Au} / \mathrm{Pt}$ star@S-S@rHSA-FA@IR780@GOx+TA. (B) fluorescence spectra of glucose + TA (control), glucose + Au/Pt star@S-S@rHSA-FA + TA, glucose + Au/Pt star@S-S@rHSA-FA@GOx + TA and glucose + Au/Pt star@S-S@rHSA-FA@IR780@GOx + TA. Parameters: $\left[\mathrm{H}_{2} \mathrm{O}_{2}\right]: 100 \mu \mathrm{M}$, [Au/Pt star@S-S@rHSA-FA]: 50 m/mL, [Au/Pt star@S-S@rHSA-FA@GOx]: $55 \mu \mathrm{g} / \mathrm{mL}$, [Au/Pt star@S-S@rHSA-FA@IR780@GOx]: $66 \mu \mathrm{g} / \mathrm{mL}$, [glucose]: $5 \mathrm{mM}$. (C) Fluorescence curves of SOSG for singlet oxygen $\left({ }^{1} \mathrm{O}_{2}\right)$ determination from free IR780 and probes in absence or presence of laser irradiation. (D) Temperature fluctuation of PBS (control) and probes (IR780 content: $20,60 \mu \mathrm{g} / \mathrm{mL})$ under $808 \mathrm{~nm}$ laser irradiation $\left(1.0 \mathrm{~W} / \mathrm{cm}^{2}\right)$ during $300 \mathrm{~s}$ $(\mathrm{n}=3)$. The inset: photo-thermal pictures after 5 min irradiation. (E) Cumulative release of IR780 from probes dependent with GSH concentrations $(0,10$ and 50 
$\mathrm{mM}$ ) at $\mathrm{pH} 7.4$ within $24 \mathrm{~h}$. (F) Fluorescence curves of IR780 at different concentrations ( $\lambda$ ex: $780 \mathrm{~nm}$ ). Inset: Calibration curve of IR780 fluorescence intensity and concentration.

\subsection{In Vitro GSH-dependent IR780 releasing of Au/Pt star@S-S@rHSA-FA@IR780}

The GSH-responsive property of probes was investigated by monitoring the fluorescence intensities of released IR780 due to the interaction between probes and GSH. As shown in Fig. 3E, cumulative release of IR780 from probes reached to $10.3 \%$ (no GSH), $64 \%$ (10 mM GSH) and 80.30\% (50 mM GSH) within 24 $\mathrm{h}$, indicating that our constructed probes presented an GSH-dependent IR780 releasing due to the favorable cleavage ability toward disulfide linker of probes by GSH. Moreover, the amount of released IR780 was calculated according to the calibration curve between fluorescence intensity and IR780 concentrations (shown in Fig. 3F). Here mentioned results indicated that our prepared probes demonstrated favorable IR780 releasing response to GSH, which could enhance probes' therapeutic performance in unique tumor microenvironment.

\subsection{Cellular uptake and intracellular distribution}

The target effect and cellular uptake efficiency at various times between cells and materials (free IR780 and probes) were studied by synergistically using CLCM and FC (Fig. 4 A-B). As demonstrated in Fig. 4A, the fluorescence intensity of IR780 (red signal) in both groups were enhanced as the interaction time prolonged, suggesting gradual increment of the cellular uptake. And, the blue fluorescence signal reflected the location of cell nuclei stained by DAPI dye. Comparing the confocal images of cells treated with IR780 and probes in respective, we could find that the fluorescence signal of IR780 in probes was brighter than the free IR780 groups, proving easy endocytosis of the probes by cancer cells due to specifically targeted recognition of FA to MGA-803 cells.

To quantitatively study the cellular uptake efficiency of probes, the red fluorescence values in cells were calculated by FC. As exhibited in Fig. 4B, the signal values were increased with the interacted time between the materials and cells, and the intensity value of free IR780 and probes were calculated into 292 and 385 in respective after $12 \mathrm{~h}$ internalization, suggesting that probes could be acted as excellent carriers to transport numerous dye IR780 molecules. All above-discussed results concluded that the final-obtained probes presented an efficient cellular uptake, which was beneficial for the following in vivo therapy.
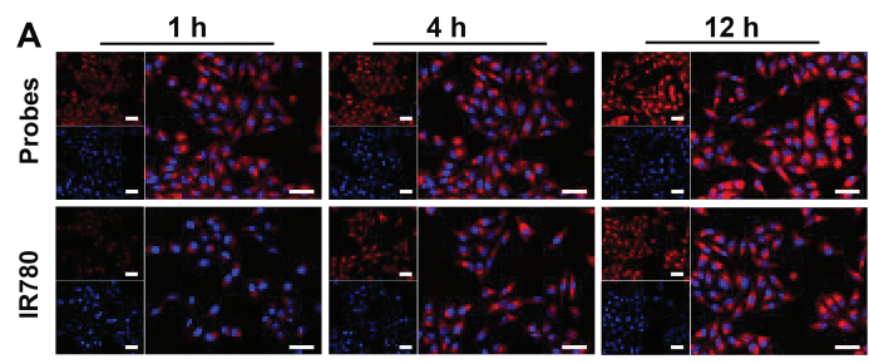

B

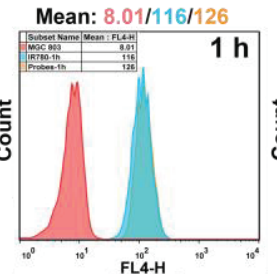

Mean: $8.01 / 177 / 271$
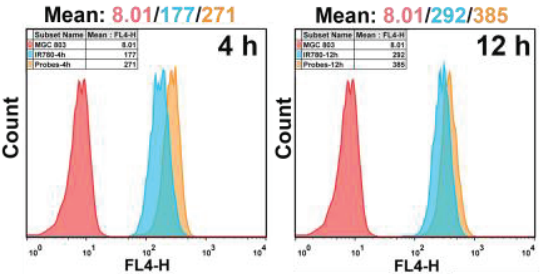

Fig. 4. Cellular uptake analysis. (A) CLSM pictures of cells incubated with free IR780 and probes at various times (1, 4, 12 h). Scale bar: $50 \mu \mathrm{m}$. (B) Quantitative investigation of the cellular uptake efficiency by FC.

\subsection{In vitro photo-induced cell toxicity.}

To superiorly investigate the photo-induced therapy efficacy of probes towards the MGC- 803 cells, the safe concentration of various materials was applied in cell toxicity assay, ensuring the favorable biocompatibility and excellent cell viability of various materials in dark. Firstly, we evaluated the cellular proliferation inhibition of various materials without laser irradiation. As demonstrated in the CCK-8 assay (Fig. 5A), we could observed that the experimental groups including free IR780, $\mathrm{Au} / \mathrm{Pt}$ star@S-S@rHSA-FA@GOx and probes ([IR780]: 0.25-3 $\mu \mathrm{g} / \mathrm{mL}$, [Au/Pt star@S-S@rHSA-FA@GOx]: 1.25-15 $\mu \mathrm{g} / \mathrm{mL}$ ) exhibited great biocompatibility towards cells in dark. However, when given the $808 \mathrm{~nm}$ laser irradiation, the survival rate of cells showed an obvious decrement upon the increasing of concentrations in free IR780, Au/Pt star@S-S@rHSA-FA@GOx and probes groups. Typically, compared with free IR780 or Au/Pt star@S-S@rHSA-FA@GOx group, the cell viability of probes group in presence of laser irradiation was much lower and reached to $35 \%$ when the concentration of probes were at $18 \mu \mathrm{g} / \mathrm{mL}$, meanwhile the concentration of IR780 was at $3 \mu \mathrm{g} / \mathrm{mL}$ and $\mathrm{Au} / \mathrm{Pt}$ star@S-S@rHSA-FA@GOx was at $15 \mu \mathrm{g} / \mathrm{mL}$, indicating that here constructed probes performed an outstanding photo-induced therapy effect. The favorable photo-induced therapy in probes group might be attributed to the synergistic PTT therapy of IR780 and Au/Pt star@S-S@rHSA-FA, the PDT therapy of IR780 as well as the favorable targeting ability of the FA in probes.

Meantime, the FC was carried out to investigate the survival rate of cells after interacted with PBS, free IR780 (3 $\mu \mathrm{g} / \mathrm{mL}), \mathrm{Au} / \mathrm{Pt}$ star@S-S@rHSA-FA@GOx $(15 \mu \mathrm{g} / \mathrm{mL})$ and probes $(12 \mu \mathrm{g} / \mathrm{mL})$ with or without $808 \mathrm{~nm}$ laser irradiation for $5 \mathrm{~min}$. And, the cells were dually labeled by Annexin V-FITC and propidium iodide (PI). As showed in Fig. 5B, no obvious cell apoptosis appeared in the PBS group in dark or irradiation, indicating the relative safety of laser power to cells. In addition, the cells interacted free IR780 (3 $\mu \mathrm{g} / \mathrm{mL}), \mathrm{Au} / \mathrm{Pt}$ star@S-S@rHSA-FA@GOx $(15 \mu \mathrm{g} / \mathrm{mL})$ and probes $(18 \mu \mathrm{g} / \mathrm{mL})$ in dark showed no change in cell apoptosis. However, after $808 \mathrm{~nm}$ laser irradiating, the cells incubated with free IR780 (3 $\mu \mathrm{g} / \mathrm{mL}), \mathrm{Au} / \mathrm{Pt}$ star@S-S@rHSA-FA@GOx (15 $\mu \mathrm{g} / \mathrm{mL})$ and 
probes $(18 \mu \mathrm{g} / \mathrm{mL})$ presented cell apoptosis, and the cells in probes groups were at the highest death rate.

For visually observing the therapy effect of probes upon the laser irradiation, Calcein-AM and PI staining method was used to analyze the cell viability. Herein, red fluorescence of PI revealed dead cells while green fluorescence of calcine AM shown live cells As exhibited in Fig. 5C, there was almost no red fluorescence signal showed in the cells incubated with probes $(18 \mu \mathrm{g} / \mathrm{mL})$ in dark, indicating no obvious dead cells generated without irradiating. In contrast, the strong red fluorescence signal showed in the cells after $808 \mathrm{~nm}$ laser irradiation, proving visual cells death appeared after irradiation and remarkable therapeutic efficacy of here constructed probes. The results acquired here totally reconfirmed the CCK-8 assay and FC measurement above.
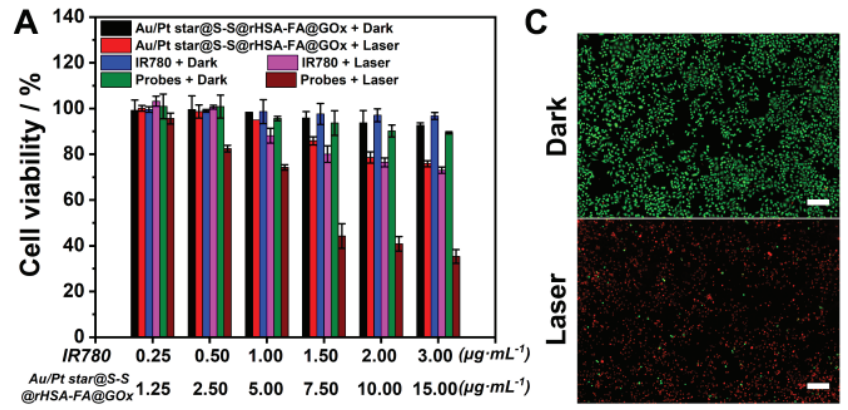

B

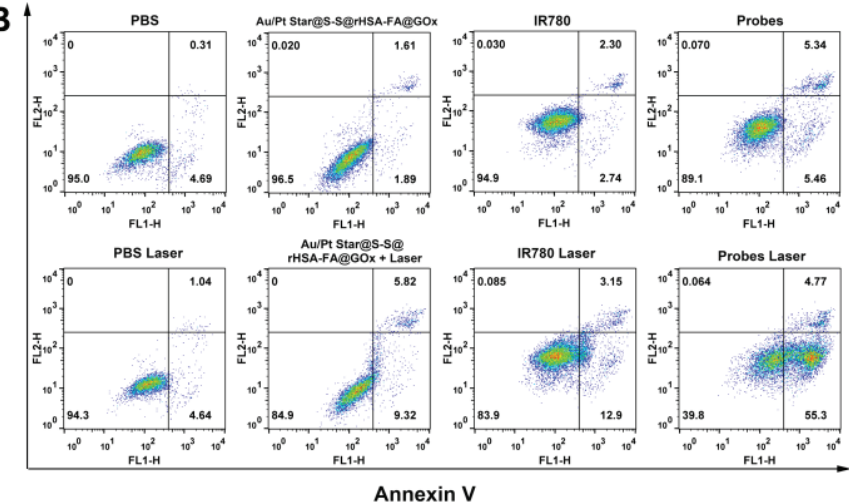

Fig. 5. Cell toxicity assay: (A) CCK- 8 assay (n=5), (B) FC study and (C) Calcein-AM and PI staining measurement (Scale bar: $200 \mu \mathrm{m}$ ) for investigation of dark toxicity and photo toxicity.

\subsection{Cellular ROS analysis}

When Au/Pt star@S-S@rHSA-FA@IR780@GOx were ingested by cancer cells, the special metabolism of cancer cells and GOx-mediated glucose consumption might led to significant increment of $\mathrm{H}_{2} \mathrm{O}_{2}$ in cells, resulting noninvasive cancer starvation, gluconic acid-activated acidity enhancement and toxic hydroxyl radical $(\cdot \mathrm{OH})$ induced cells apoptosis based on the reaction between $\mathrm{Au} / \mathrm{Pt}$ star nanoparticles and $\mathrm{H}_{2} \mathrm{O}_{2}$. To study the cellular $\cdot \mathrm{OH}$ production based on the sequential catalysis reactions from $\mathrm{GOx}$ and $\mathrm{Au} / \mathrm{Pt}$ star, the $\mathrm{H}_{2} \mathrm{DCFDA}$ dye was applied to stain cells after the cells were incubated with $\mathrm{Au} / \mathrm{Pt}$ star@S-S@rHSA-FA@GOx (0 to $200 \mu \mathrm{g} / \mathrm{mL}$ ) by using complete medium in low glucose, and then the stained cells were investigated by CLSM and FC. As shown in confocal images of Fig. 6A, the green fluorescence signal was gradually enhanced with the increasing of Au/Pt star@S-S@rHSA-FA@GOx concentration, revealing the obvious ROS could be generated by decomposing endogenous $\mathrm{H}_{2} \mathrm{O}_{2}$. Furthermore, the fluorescence value collected from flow cytometry could quantitatively validate above-mentioned results. As showed in Fig. 6B, the fluorescence value of green signal was proportional to the concentration of Au/Pt star@S-S@rHSA-FA@GOx, and increased to 2436 when the concentration of Au/Pt star@S-S@rHSA-FA@GOx reached to $200 \mu \mathrm{g} / \mathrm{mL}$, showing admirable peroxidase property of $\mathrm{Au} / \mathrm{Pt}$ star@S-S@rHSA-FA@GOx in producing toxic·OH after targeted enrichment at the tumor site.

Besides, the photo-induced PDT based on IR780 also played a crucial role in cancer therapy. To investigate intracellular ROS production of different materials under laser irradiation, the cells were firstly incubated with various materials at relatively safe concentrations. The cells were firstly incubated with PBS, free IR780 (3 $\mu \mathrm{g} / \mathrm{mL})$, Au/Pt star@S-S@rHSA-FA@GOx $(15 \mu \mathrm{g} / \mathrm{mL})$ and probes $(18 \mu \mathrm{g} / \mathrm{mL})$ in respective, and treated without or with irradiation, and finally stained by $\mathrm{H}_{2}$ DCFDA dye. Here, the CLSM were carried out to study the ROS generation of various materials in cells. As shown in the CLSM images of Fig. 6C, no fluorescence signals were collected in PBS and IR780 groups when in dark, while slight fluorescence signals were showed in the $\mathrm{Au} / \mathrm{Pt}$ star@S-S@rHSA-FA@GOx and probes groups in absence or presence of laser, suggesting the $\mathrm{Au} / \mathrm{Pt}$ star in probes could be acted as peroxidase to catalyze the $\mathrm{H}_{2} \mathrm{O}_{2}$ and produced $\cdot \mathrm{OH}$ at both dark and irradiation. Notably, compared with other groups, obvious and strong green fluorescence could be observed in IR780 and probes under irradiation, indicating that IR780 could effectively generate ROS in the presence of laser irradiation. Moreover, the strongest fluorescence signal was collected from the probes group, revealing remarkable ROS generation efficacy based on IR780 and $\mathrm{Au} / \mathrm{Pt}$ star of probes under irradiating.

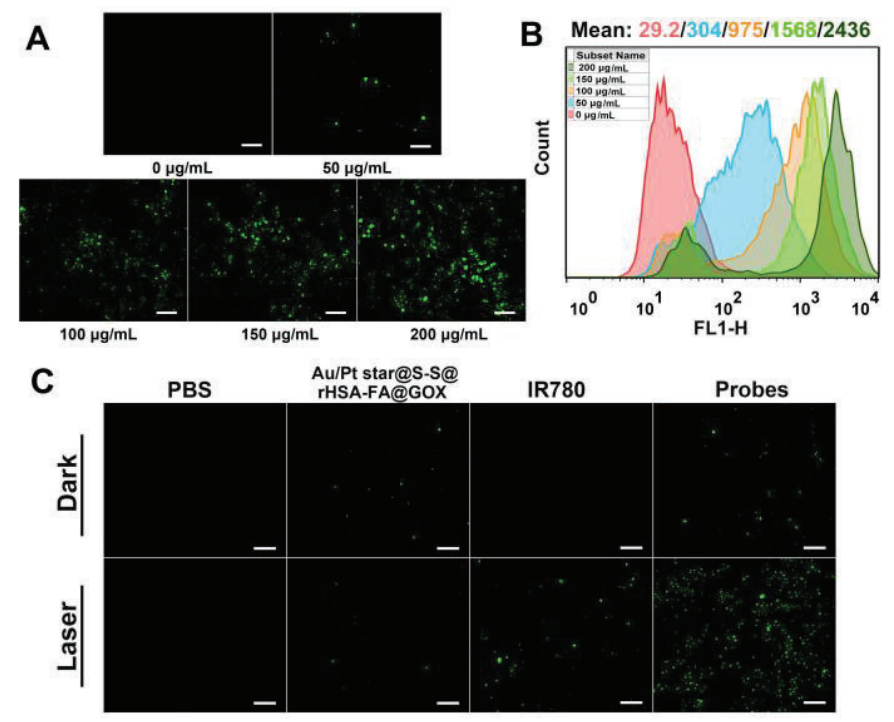

Fig. 6. Cellular ROS analysis: (A) Confocal images of Cells interacted with Au/Pt star@S-S@rHSA-FA@GOx at various concentration (0 to $200 \mu \mathrm{g} / \mathrm{mL})$. scale bar: $100 \mu \mathrm{m}$. (B) Green fluorescence value at various concentration ( 0 to $200 \mu \mathrm{g} / \mathrm{mL}$ ) recorded by flow cytometry. (C) CLSM imaging of cells treated with various materials without irradiation ("dark") or with irradiation ("laser"). scale bar: $100 \mu \mathrm{m}$. (Green signal: carboxy-H2DCFDA dye stained cell to reflect ROS generation)

3.8 In vivo tumor-targeted evaluation based on real-time fluorescence imaging 
The tumor-targeting abilities of various materials have been investigated by tracking in vivo fluorescence images of free IR780 and probes after tail vein injection into MGC803-tumor bearing mice, and free IR780 was acted as a control. As showed in Fig. 7A, free IR780 exhibited a relatively weak fluorescence intensity in tumor sites at different time, while obvious fluorescence signals were appeared in the tumor site of the probes treated mice, suggesting favorable tumor-targeting capabilities of constructed probes. In addition, more and more probes accumulated in the tumor tissue with prolonging the circulation time from 2 to $36 \mathrm{~h}$, and still displayed remarkable signal after $48 \mathrm{~h}$ post-injection. However, in free IR780 group, there were gradually reducing red fluorescent signals in tumor site after $24 \mathrm{~h}$ post-injection, and displayed a weak tumor fluorescent signal in $48 \mathrm{~h}$, suggesting that small IR780 molecules could be quickly excreted from body and slightly accumulated in tumor site. As shown in Fig. 7B, the fluorescence intensity value was quantitatively measured. The mean fluorescence value collected from probes group was stronger than that in free IR780 group at every time point, and reached maximal value at $36 \mathrm{~h}$. Additionally, there was still strong intensity value even that the circulation time was up to $48 \mathrm{~h}$. In contrast, the intensity values in free IR780 were low in all time points, and began to decrease at $36 \mathrm{~h}$. All above-discussed results indicated that here prepared probes revealed good targeted accumulation and long retention time, endowing potentially effective therapy based on abundant probes.

To investigate the body distribution of probes and IR780, organs and tumor were excised after $48 \mathrm{~h}$ post-injection and imaged on an optical imaging technique. As illustrated in Fig. 7C, there was weak fluorescence exhibited in the tumor of free IR780 treated mice while an obvious accumulation showed in the tumor region of probes treated mice, confirming above-acquired results in vivo tumor-targeted fluorescence imaging. Moreover, the result of coupled plasma mass spectrometry (ICP-MS) proved that some nanoprobes aggerated in tumor site and some organs (liver, spleen and lung) after $48 \mathrm{~h}$ treatment. The accumulation in liver, spleen and lung may cause by partial interception of reticuloendothelial system (data shown in Fig. S4) [17]. intravenously injected with free IR780 and probes (Au/Pt star@S-S@rHSA-FA@IR780@GOx) at various time point from 2 h to 60 h (Parameters: excitation at $710 \mathrm{~nm}$, emission at $790 \mathrm{~nm}$, integration time in $60 \mathrm{~s}$ ).
(B) Fluorescence intensity in tumor region prolonging with time. (C) Fluorescence images of organs (heart, liver, spleen, lungs, and kidney) and tumors from free IR780 and probes treated mice after $48 \mathrm{~h}$ post-injection.

\subsection{The therapy effect of probes in Tumor-Bearing Mice}

Finally, the therapeutic effect of probes was studied by using MGC-803 tumor-bearing mice. Firstly, the mice were treated with PBS, free IR780, Au/Pt star@S-S@rHSA-FA@GOx or probes (1 mg/kg of IR780, 5 mg/kg of Au/Pt star@S-S@rHSA-FA@GOx) in respective. After circulation for $36 \mathrm{~h}$, the tumor region of mice was illuminated by $808 \mathrm{~nm}$ laser $\left(1.0 \mathrm{~W} / \mathrm{cm}^{2}, 5 \mathrm{~min}\right)$, and the temperature fluctuation at tumor sites was monitored by a NIR camera. As illustrated in Fig. 8A, the temperatures were increased with prolonging of irradiation time within $5 \mathrm{~min}$. Among various groups, after $5 \mathrm{~min}$ irradiation in $1.0 \mathrm{~W} / \mathrm{cm}^{2}$, the temperatures in tumor of Au/Pt star@S-S@rHSA-FA@GOx, free IR780 and probes groups could reach to $47.9{ }^{\circ} \mathrm{C}, 49.7{ }^{\circ} \mathrm{C}$ and $56.1{ }^{\circ} \mathrm{C}$ respectively, showing the superior PTT therapy efficacy of probes due to the irreversible damage aroused by laser irradiation. However, the temperature in tumor site of PBS-treated mice was increased to $39.2^{\circ} \mathrm{C}$, proving safe irradiation power and time.

Then tumor size change and the bodyweight fluctuation of various materials treated mice were recorded to exhibit the therapy effect. As showed in Fig. 8B, the PBS groups in dark and irradiation as well as the IR780 group in absence of irradiation showed the almost same growth rate of tumor and the relative tumor volume $\left(\mathrm{V} / \mathrm{V}_{0}\right)$ reached to the highest among all groups $(\mathrm{V}$ : real-time volume, $\mathrm{V}_{0}$ : initial tumor volume). However, when the tumor of IR780 treated mice was irradiated, the tumor showed a relatively slow growth rate compared with the mice injected with IR780 in dark, showing good PPT and PDT of IR780. Moreover, compared with PBS group, we could observe that there were almost same and low tumor increasing rate appeared in the groups including Au/Pt star@S-S@rHSA-FA@GOx and probes without irradiation, indicating potentially excellent cancer starvation therapy and enzymes oxidative therapy based on consuming glucose by GOx and generating $\mathrm{OH}$ by the reaction between $\mathrm{Au} / \mathrm{Pt}$ star and $\mathrm{H}_{2} \mathrm{O}_{2}$. Due to the NIR-resonant property of $\mathrm{Au} / \mathrm{Pt}$ star, the Au/Pt star@S-S@rHSA-FA@GOx could produce heat to damage the tumor after absorbing NIR light, and therefore the $\mathrm{Au} / \mathrm{Pt}$ star@S-S@rHSA-FA@GOx presented a lower growth rate when irradiating, proving excellent PTT effect of $\mathrm{Au} / \mathrm{Pt}$ star. Undoubtedly, owing to collaborative therapy effects of IR780, $\mathrm{Au} / \mathrm{Pt}$ star and GOx, probes displayed excellent tumor growth inhibition within 15 days.

To monitor the therapy-induced adverse collateral effect based on synthesized probes, the weight of various materials treated mice were recorded. As exhibited in the Fig. 8C, there was almost no obvious weight loss of the mice during the therapy process, indicating the favorable biocompatibility and biosafety of probes. Moreover, the tumor change during therapy process was imaged by a camera. As shown in the Fig. S5, the tumors from the mice treated with PBS under dark or laser irradiation and the tumor in IR780 under dark showed obvious growth tendency prolonged with time. And, tumors from the mice injected with $\mathrm{Au} / \mathrm{Pt}$ star@S-S@rHSA-FA@GOx and probes under dark exhibited a slower growth rate compared with PBS group due to the enzyme effect based on GOx and $\mathrm{Au} / \mathrm{Pt}$ star. Moreover, due to the 
PTT\&PDT property of IR780 and Au/Pt star, the tumor in groups contained the IR780 under irradiation, $\mathrm{Au} / \mathrm{Pt}$ star@S-S@rHSA-FA@GOx under irradiation and probes under irradiation all showed better inhibition tendency than those groups without irradiating. Notably, the tumor of probes $(\mathrm{Au} / \mathrm{Pt}$ star@S-S@rHSA-FA@GOx@IR780) treated mice showed an atrophied trend, in which obvious scar appeared after 4 days, tumor ablated and normal tissue regenerated after 15 days. After 30 days, no new tumor tissue regenerated (showed in Fig. S6), indicating the favorable therapy effect of constructed $\mathrm{Au} / \mathrm{Pt}$ star@S-S@rHSA-FA@IR780@GOx probes.

In addition, the organs (heart, liver, spleen, lung and kidney) of probes treated mice were stained by $H \& E$ dye to investigate histopathological examination. As showed in Fig. 8D, there was no noticeable sign of pathological damage appeared in the main organs, further suggesting good biocompatibility of probes in mice.

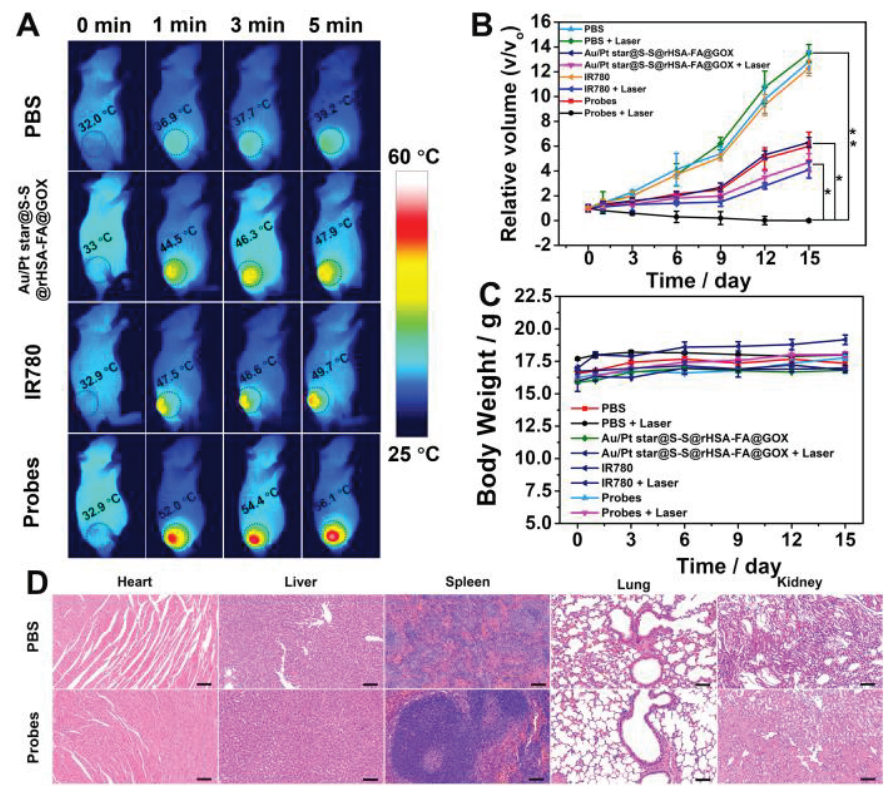

Fig. 8. (A) Infrared thermal imaging of mice injected with PBS, free IR780, Au/Pt star@S-S@rHSA-FA@GOx and Au/Pt star@S-S@rHSA-FA@IR780@GOx (1 mg/kg of IR780, 5 mg/kg of Au/Pt star@S-S@rHSA-FA@GOx) to study the tumor temperature change prolonging with irradiation time $\left(1.0 \mathrm{~W} / \mathrm{cm}^{2}, 808 \mathrm{~nm}\right)$. (B) Relative tumor volume variation in different materials treated mice with or without lasering. ( $\mathrm{n}=5, * \mathrm{P}<0.05, * * \mathrm{P}$ $<0.01$ ). (C) Body weight change of various materials treated mice with or without lasering. (D) H\&E study of main organs from PBS and probes treated mice after 15 days. Scale bar: $100 \mu \mathrm{m}$.

\section{Conclusions}

In this work, we introduced multifunctional probes $(\mathrm{Au} / \mathrm{Pt}$ star@S-S@rHSA-FA@IR780@GOx) used for gastric cancer diagnosis and therapy, which possessed excellent targeted effect, real-time imaging, favorable GSH-responsive property and prominent therapy effect combining glucose starving-like therapy/enzyme oxidative therapy/PTT/PDT. Interesting, as the constructed probes were specifically targeted to the tumor sites, sequential reactions including GSH-sensitive IR780 releasing, nutrients (glucose and $\mathrm{O}_{2}$ ) depletion by GOx to generate $\mathrm{H}_{2} \mathrm{O}_{2}$ and enhance acidity, Fenton-like reaction between $\mathrm{Pt}$ nanolayer and $\mathrm{H}_{2} \mathrm{O}_{2}$ to produce toxic $\cdot \mathrm{OH}$, and IR780 induced PTT/PDT under
$808 \mathrm{~nm}$ irradiation would occur, achieving prominent theragnostic with real-time imaging and synergetic cancer starving-like therapy/enzyme oxidative therapy/PTT/PDT feature. In the result, the tumor was ablated and without regeneration after 30 days. All above-demonstrated results suggested that our preliminary work provided an eminent strategy for tumor theragnostic by using the specific tumor environment and assembling cancer starvation/enzyme catalysis/PTT\&PDT treatment

\section{Acknowledgements}

We thanks the support of the National Foundational Basic Research Project of China (2017YFA0205301 and 2015CB931802), National Nature Scientific foundation (81903169, 81803094, 81602184, 81822024 and 81571729), Shanghai Municipal Commission of Economy and Information Technology Fund (NO. XC-ZXSJ-02-2016-05), the medical engineering cross project of Shanghai Jiao Tong university(YG2016ZD10 and YG2017Z D05), the Project of Thousand Youth Talents from China, and the National Key Research and Development Program of China (2017YFC1200904). We also are grateful for the financial support of Shanghai Sailing Program (No. 19YF1422300), Sponsor from Startup Fund for Yongman Research at SJTU (No.18X100040044) and Shanghai Engineering Research Center for Intelligent Diagnosis and Treatment Instrument (No.15DZ2252000) are also acknowledged.

Electronic Supplementary Material: Supplementary material (TEM image of $\mathrm{Au} / \mathrm{Pt}$ star, FTIR spectra of various materials, UV-vis absorbance spectra of IR780, Tumor change pictures prolonging with time, Picture of mice treated with probes after 30 days) is available in the online version of this article at http://dx.doi.org/10.1007/s12274-***_******

\section{References}

[1] Stefan Harmsen, R. H.; Matthew A. Wall; Hazem Karabeber; Jason M. Samii; Massimiliano Spaliviero; Julie R. White; Sébastien Monette; Rachael O'Connor; Kenneth L. Pitter; Stephen A. Sastra; Michael Saborowski; Eric C. Holland; Samuel Singer; Kenneth P. Olive; Scott W. Lowe; Ronald G. Blasberg; Moritz F. Kircher. Surface-enhanced resonance Raman scattering nanostars for high-precision cancer imaging. Science Translational Medicine 2015, 7.

[2] Zhang, C.;Li, C.;Liu, Y.;Zhang, J.;Bao, C.;Liang, S.;Wang, Q.;Yang, Y.;Fu, H.;Wang, K.; Cui, D. Gold Nanoclusters-Based Nanoprobes for Simultaneous Fluorescence Imaging and Targeted Photodynamic Therapy with Superior Penetration and Retention Behavior in Tumors. Advanced Functional Materials 2015, 25, 1314-1325.

[3] Zhu, P.;Chen, Y.; Shi, J. L. Nanoenzyme-Augmented Cancer Sonodynamic Therapy by Catalytic Tumor Oxygenation. Acs Nano 2018, 12, 3780-3795.

[4] Alves, C. G.;Lima-Sousa, R.;de Melo-Diogo, D.;Louro, R. O.; Correia, I. J. IR780 based nanomaterials for cancer imaging and photothermal, photodynamic and combinatorial therapies. Int J Pharm 2018, 542, 164-175. 
Liu, Y.;Yang, M.;Zhang, J.;Zhi, X.;Li, C.;Zhang, C.;Pan, F.;Wang, K.;Yang, Y.;Martinez de la Fuentea, J.; Cui, D. Human Induced Pluripotent Stem Cells for Tumor Targeted Delivery of Gold Nanorods and Enhanced Photothermal Therapy. ACS Nano 2016, 10, 2375-2385.

[6] Zhang, Q.;Yin, T.;Gao, G.;Shapter, J. G.;Lai, W.;Huang, P.;Qi, W.;Song, J.; Cui, D. Multifunctional Core@Shell Magnetic Nanoprobes for Enhancing Targeted Magnetic Resonance Imaging and Fluorescent Labeling in Vitro and in Vivo. Acs Applied Materials \& Interfaces 2017, 9, 17777-17785.

[7] Yuan, A.;Qiu, X.;Tang, X.;Liu, W.;Wu, J.; Hu, Y. Self-assembled PEG-IR-780-C13 micelle as a targeting, safe and highly-effective photothermal agent for in vivo imaging and cancer therapy. Biomaterials 2015, 51, 184-193.

[8] Hou, W.;Xia, F.;Alves, C. S.;Qian, X.;Yang, Y.; Cui, D. MMP2-Targeting and Redox-Responsive PEGylated Chlorin e6 Nanoparticles for Cancer Near-Infrared Imaging and Photodynamic Therapy. ACS Appl Mater Interfaces 2016, 8, 1447-1457.

[9] Zhang, Y.;Zhang, Q.;Zhang, A.;Pan, S.;Cheng, J.;Zhi, X.;Ding, X.;Hong, L.;Zi, M.;Cui, D.; He, J. Multifunctional co-loaded magnetic nanocapsules for enhancing targeted MR imaging and in vivo photodynamic therapy. Nanomedicine 2019, 21, 102047.

[10] Zhang, E.;Luo, S.;Tan, X.; Shi, C. Mechanistic study of IR-780 dye as a potential tumor targeting and drug delivery agent. Biomaterials 2014, 35, 771-778.

[11] Peng, C.;Xing, H.;Fan, X.;Xue, Y.;Li, J.; Wang, E. Glutathione Regulated Inner Filter Effect of $\mathrm{MnO} 2$ Nanosheets on Boron Nitride Quantum Dots for Sensitive Assay. Anal Chem 2019, 91, 5762-5767.

[12] Sun, J.;Liu, F.;Yu, W.;Jiang, Q.;Hu, J.;Liu, Y.;Wang, F.; Liu, X. Highly sensitive glutathione assay and intracellular imaging with functionalized semiconductor quantum dots. Nanoscale 2019, 11, 5014-5020.

[13] Liu, Z.;Shen, N.;Tang, Z.;Zhang, D.;Ma, L.;Yang, C.; Chen, X. An eximious and affordable GSH stimulus-responsive poly(alpha-lipoic acid) nanocarrier bonding combretastatin A4 for tumor therapy. Biomater Sci 2019 , $10.1039 / \mathrm{c} 9 \mathrm{bm} 00002 \mathrm{j}$.

[14] Huo, M.;Wang, L.;Chen, Y.; Shi, J. Tumor-selective catalytic nanomedicine by nanocatalyst delivery. Nat Commun 2017, 8, 357.

[15] Fu, L. H.;Qi, C.;Lin, J.; Huang, P. Catalytic chemistry of glucose oxidase in cancer diagnosis and treatment. Chem Soc Rev 2018, 47, 6454-6472.
Chang, K.;Liu, Z.;Fang, X.;Chen, H.;Men, X.;Yuan, Y.;Sun, K.;Zhang, X.;Yuan, Z.; Wu, C. Enhanced Phototherapy by Nanoparticle-Enzyme via Generation and Photolysis of Hydrogen Peroxide. Nano Lett 2017, 17, 4323-4329.

[17] Wang, Z.;Zhang, Y.;Ju, E.;Liu, Z.;Cao, F.;Chen, Z.;Ren, J.; $\mathrm{Qu}, \mathrm{X}$. Biomimetic nanoflowers by self-assembly of nanozymes to induce intracellular oxidative damage against hypoxic tumors. Nat Commun 2018, 9, 3334.

[18] Fan, W.;Yung, B.;Huang, P.; Chen, X. Nanotechnology for Multimodal Synergistic Cancer Therapy. Chemical reviews 2017, 117, 13566-13638.

[19] Wang, X.;Hu, Y.; Wei, H. Nanozymes in bionanotechnology: from sensing to therapeutics and beyond. Inorganic Chemistry Frontiers 2016, 3, 41-60.

[20] Jiang, D.;Ni, D.;Rosenkrans, Z. T.;Huang, P.;Yan, X.; Cai, W. Nanozyme: new horizons for responsive biomedical applications. Chem Soc Rev 2019, 48, 3683-3704.

[21] Zhao, M.;Deng, K.;He, L.;Liu, Y.;Li, G.;Zhao, H.; Tang, Z. Core-shell palladium nanoparticle@metal-organic frameworks as multifunctional catalysts for cascade reactions. J Am Chem Soc 2014, 136, 1738-1741.

Du, K.;Liu, Q.;Liu, M.;Lv, R.;He, N.; Wang, Z. Encapsulation of glucose oxidase in $\mathrm{Fe}(\mathrm{III}) /$ tannic acid nanocomposites for effective tumor ablation via Fenton reaction. Nanotechnology 2019, 31, 015101 .

[23] Liu, M.;Liu, B.;Liu, Q.;Du, K.;Wang, Z.; He, N. Nanomaterial-induced ferroptosis for cancer specific therapy. Coordin Chem Rev 2019, 382, 160-180.

[24] Lyu, Y.;Tian, J.;Li, J.;Chen, P.; Pu, K. Semiconducting Polymer Nanobiocatalysts for Photoactivation of Intracellular Redox Reactions. Angew Chem Int Ed Engl 2018, 57, 13484-13488.

[25] Li, J.;Xie, C.;Huang, J.;Jiang, Y.;Miao, Q.; Pu, K. Semiconducting Polymer Nanoenzymes with Photothermic Activity for Enhanced Cancer Therapy. Angew Chem Int Ed Engl 2018, 57, 3995-3998.

[26] Song, Y.;Qu, K.;Zhao, C.;Ren, J.; Qu, X. Graphene oxide: intrinsic peroxidase catalytic activity and its application to glucose detection. Adv Mater 2010, 22, 2206-2210.

[27] Gao, S.;Lin, H.;Zhang, H.;Yao, H.;Chen, Y.; Shi, J. Nanocatalytic Tumor Therapy by Biomimetic Dual Inorganic Nanozyme-Catalyzed Cascade Reaction. Adv Sci (Weinh) 2019, 6, 1801733.

[28] Huang, Y.;Ren, J.; Qu, X. Nanozymes: Classification, Catalytic Mechanisms, Activity Regulation, and Applications. Chemical reviews 2019, 119, 4357-4412. 
Zhang, L.;Xia, K.;Lu, Z.;Li, G.;Chen, J.;Deng, Y.;Li, S.;Zhou, F.; He, N. Efficient and Facile Synthesis of Gold Nanorods with Finely Tunable Plasmonic Peaks from Visible to Near-IR Range. Chem Mater 2014, 26, 1794-1798.

[30] Zhang, L. X., Kai; Bai, Ying-Ying; Lu, Zhuoxuan; Tang, Yongjun; Deng, Yan; Chen, Juan; Qian, Weiping; Shen, He; Zhang, Zhijun; Ju, Shenghong; He, Nongyue Synthesis of Gold Nanorods and Their Functionalization with Bovine Serum Albumin for Optical Hyperthermia. J Biomed Nanotechnol 2014, 10, 1440-1449.

[31] Zhi, X.;Liu, Y.;Lin, L.;Yang, M.;Zhang, L.;Zhang, L.;Liu, Y.;Alfranca, G.;Ma, L.;Zhang, Q.;Fu, H.;Conde, J.;Ding, X.;Chen, D.;Ni, J.;Song, J.; Cui, D. Oral pH sensitive GNS@ab nanoprobes for targeted therapy of Helicobacter pylori without disturbance gut microbiome. Nanomedicine 2019, 20, 102019.

[32] Gao, Y.;Li, Y.;Chen, J.;Zhu, S.;Liu, X.;Zhou, L.;Shi, P.;Niu, D.;Gu, J.; Shi, J. Multifunctional gold nanostar-based nanocomposite: Synthesis and application for noninvasive MR-SERS imaging-guided photothermal ablation. Biomaterials 2015, 60, 31-41.

[33] Liang, S.;Li, C.;Zhang, C.;Chen, Y.;Xu, L.;Bao, C.;Wang, X.;Liu, G.;Zhang, F.; Cui, D. CD44v6 Monoclonal Antibody-Conjugated Gold Nanostars for Targeted Photoacoustic Imaging and Plasmonic Photothermal Therapy of Gastric Cancer Stem-like Cells. Theranostics 2015, 5, 970-984.

[34] Chen, H.;Qiu, Q.;Sharif, S.;Ying, S.;Wang, Y.; Ying, Y. Solution-Phase Synthesis of Platinum Nanoparticle-Decorated Metal-Organic Framework Hybrid Nanomaterials as Biomimetic Nanoenzymes for Biosensing Applications. ACS Appl Mater Interfaces 2018, 10, 24108-24115.

[35] Wu, J.;Qin, K.;Yuan, D.;Tan, J.;Qin, L.;Zhang, X.; Wei, H. Rational Design of Au@Pt Multibranched Nanostructures as Bifunctional Nanozymes. ACS Appl Mater Interfaces 2018, 10, 12954-12959.

[36] Zhang, A.;Pan, S.;Zhang, Y.;Chang, J.;Cheng, J.;Huang, Z.;Li, T.;Zhang, C.;de la Fuentea, J. M.;Zhang, Q.; Cui, D. Carbon-gold hybrid nanoprobes for real-time imaging, photothermal/photodynamic and nanozyme oxidative therapy. Theranostics 2019, 9, 3443-3458.

[37] Yayapao, O.; Thongtem, T.;Phuruangrat, A.; Thongtem, S. CTAB-assisted hydrothermal synthesis of tungsten oxide microflowers. J Alloy Compd 2011, 509, 2294-2299. nonenzymatic glucose sensor based on highly dispersed $\mathrm{Pt}$ nanoparticles supported on carbon nanotubes. Talanta 2007, 72, 819-824.

[39] Guo, M. Q.;Hong, H. S.;Tang, X. N.;Fang, H. D.; Xu, X. H. Ultrasonic electrodeposition of platinum nanoflowers and their application in nonenzymatic glucose sensors. Electrochim Acta 2012, 63, 1-8. 
Click here to access/download

Supplementary Material

Revised Supporting information of Au-Pt star.docx 


\section{TABLE OF CONTENTS (TOC)}

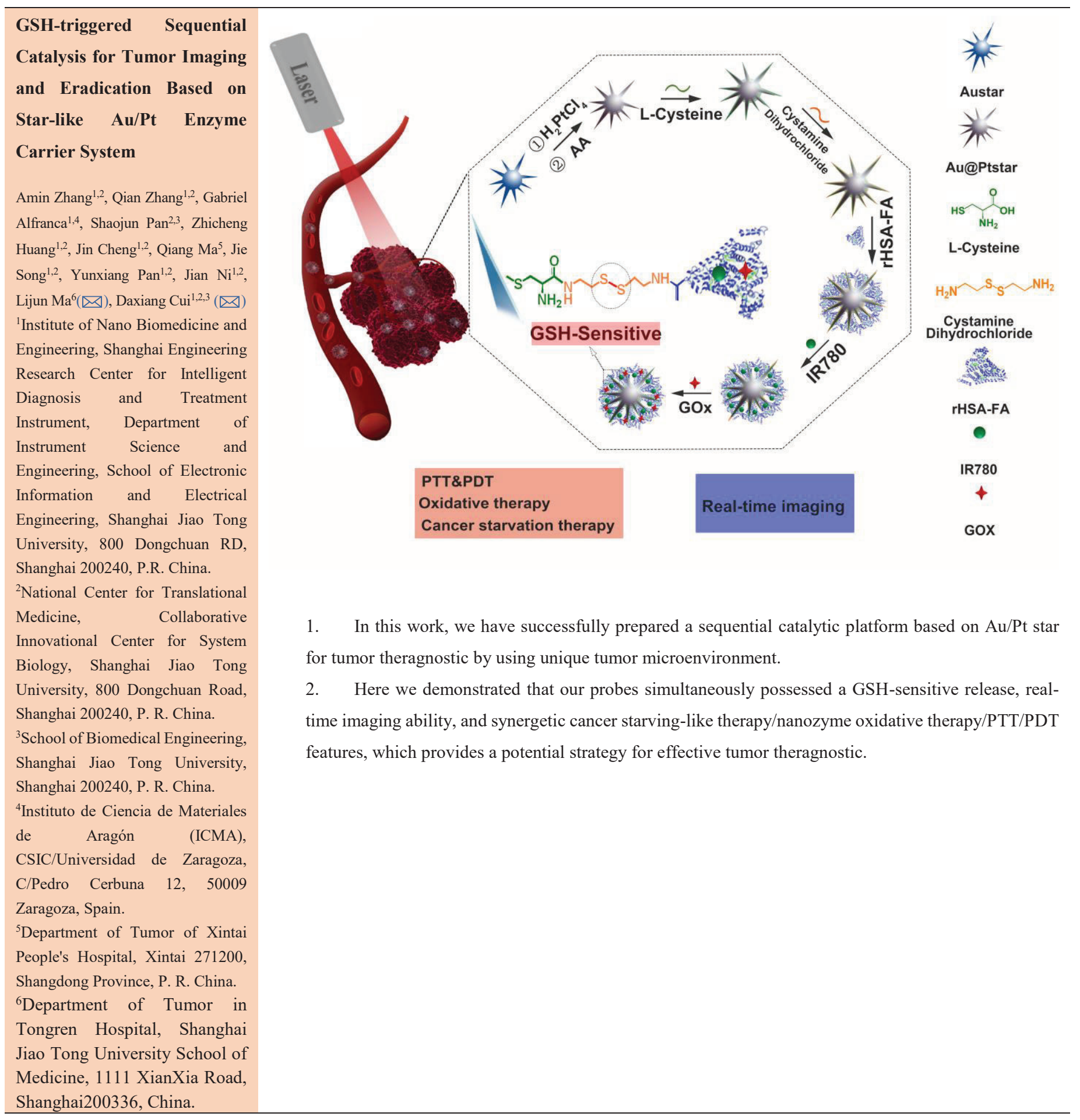

